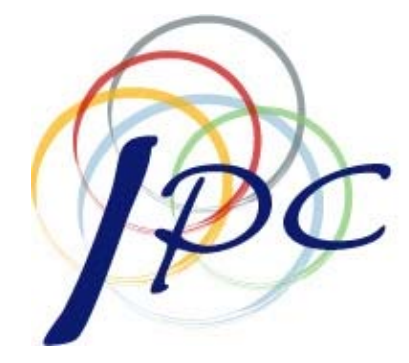

InTERnATIONAL Policy CENTER

Gerald R. Ford School of Public Policy University of Michigan

IPC Working Paper Series Number 18

\title{
Currencies, Competition, and Clans
}

\author{
Dirk Engelmann \\ Jan Hanousek \\ Evžen Kočenda
}

August 2006 


\title{
Currencies, Competition, and Clans
}

\author{
Dirk Engelmann $^{\mathrm{a}}$ \\ Jan Hanousek ${ }^{\mathrm{b}}$ \\ Evžen Kočenda ${ }^{b}$
}

\begin{abstract}
We present a theoretical and empirical analysis of the question whether stability among the world anchor currencies (G3) is attainable. The theoretical model presented in this paper builds on a model of spatial competition and rests on a set of realistic assumptions related to the behavior of central banks, workings of exchange rate regimes, geography of money, and international monetary arrangements. We show that stability is attainable in the case of two anchor currencies, but not in the case of three. The empirical evidence provides some support for assumptions and conclusions of the model.
\end{abstract}

Keywords: exchange rates, anchor currency, satellite currency, exchange rate regimes, central bank policy, monetary union, spatial competition, geography of money

JEL Classification: C72, E42, E58, N20, O23

a Dirk Engelmann, Department of Economics, Royal Holloway, University of London, TW20 0EX, United Kingdom, phone: +44 $1784 \quad 44$ 3968, email: dirk.engelmann@rhul.ac.uk

b Jan Hanousek and Evžen Kočenda, CERGE-EI, P.O.BOX 882, Politickych veznu 7 , 11121 Prague, Czech Republic. email: jan.hanousek@cerge-ei.cz, and evzen.kocenda@cerge-ei.cz

Hanousek and Kočenda hold Citibank Professorships at CERGE-EI, a joint workplace of Charles University and the Academy of Sciences of the Czech Republic. We would like to thank Benjamin Cohen, Tore Ellingsen, Randy Filer, Jan Frait, Roy Gardner, Jan Svejnar, Linda Tesar, and participants in presentations at the GDN 2005 (Dakar) and EEA 2005 (Amsterdam) conferences, and at Paris Dauphine, Pensylvania, Prague, and Michigan for helpful comments on an earlier version of the paper, and Laura Mentz for editing the manuscript. The usual disclaimer applies. 


\section{Introduction}

Since the collapse of the Bretton Woods System the world of money has been dominated by the three anchor currencies (G3) - the US dollar, the Japanese yen, and the euro (formerly the Deutsche mark). ${ }^{1}$ Cohen (1998) made a case about the power of these currencies by forging the concept of the "authoritative domain" that combines transactions and territoriality - the functional as well as physical dimensions - into a single concept of use and authority. The size of an anchor currency's authoritative domain grows when additional "satellite" currencies are linked to anchor currency via exchange rate regime. The G3 currencies are vehicle currencies whose function as an exchange medium extends far beyond domestic trade to wider use in international transactions. As a consequence, monetary transactions and their volumes represent a transmission mechanism that provides the central banks of anchor currencies control over satellite currencies. Since anchor currencies occupy larger shares of international output, trade and transactions, the economies of scale are further enhanced. And it is precisely the size of the authoritative domain that gives the issuer of a vehicle currency - central bank - power over other currencies. ${ }^{2}$ Thus, it is of pragmatic interest for the anchor currencies to capture satellite currencies.

The purpose of this paper is to analyze stability among the three anchor currencies that govern current monetary affaires. First, we introduce a two stage game to model the dynamics of how anchor currencies compete for satellite currencies. Second, we operationalize the theoretical concept of the authoritative domain developed by Cohen (1998). Third, we bring an empirical evidence to illustrate whether a tripolar currency world would, in fact, provide a workable framework to achieve the desired stability among the anchor currencies and their exchange rates.

To accomplish the above goals, we apply a model of spatial competition to assess exchange rate stability among the G3 anchor currencies using, in addition to Cohen's arguments, an historical account of existing post-war exchange rate regimes, exchange rate development, and the evolution of crucial monetary variables. We introduce a

\footnotetext{
${ }^{1}$ Given the steadily growing importance of the Deutsch mark among the European currencies after World War II, we take the liberty of extending the Deutsch mark to the euro since such continuity greatly simplifies the empirical part of this paper. There is no other motivation beyond this.

2 “Only a privileged few states with the most widely circulated currencies, such as the U.S. dollar, Europe's new euro (succeeding Germany’s Deutsche mark), and the Japanese yen, can realistically aspire to a unilateralist leadership strategy", Cohen (2004, p. xv).
} 
modification of the Hotelling (1929) location model to study the formation of areas of influence in exchange rate policy. Like firms in the Eaton and Lipsey (1975) model that compete for customers distributed along a line, we consider an analogous situation for the central banks of the anchor currencies (details are given in Section 3). Through their objective of price stability, and by using a latent variable (the major component of which is the interest rate) as a positioning instrument in a policy space, the central banks attract satellite currencies that tie to the anchor currencies via exchange rate regimes. ${ }^{3}$ The power over satellite currencies is not a one-way process. A tie between satellite currencies and an anchor currency greatly reduces volatility within such an informal currency area. Reduced volatility, in turn, promotes international trade and increases stability, further reducing the costs of business activities for all participating economies, of both anchor as well as satellite currencies. In addition, satellite currency countries also benefit from enhanced price stability if they tie their currencies to an anchor currency with lower inflation. ${ }^{4}$ To repeat, the above benefits constitute practical reasons why anchor currencies benefit when satellite currencies tie to them.

The game considered in this paper can be understood as the central banks of the anchor currencies competing for shares of the currency holdings of satellite countries; that is, those whose policy has a negligible impact. The preferences of the satellite countries for the policies of the anchor currency's central bank to which they are linked are assumed to be distributed along a line. We show that with some changes in assumptions, the results of the standard spatial competition model continue to hold. Specifically, we find for a large range of parameters stability in the case of two anchor currencies, but instability in the case of three. A caveat is that our model is highly stylized and aims at long-term behavior. ${ }^{5}$ Furthermore, the purpose of the model is less intended to provide a precise explanation of observed patterns of exchange rate development, and more to present an illustration of possible consequences if the number of anchor currencies is reduced from three to two. The empirical part of the paper provides some evidence that our assumptions are realistic and that the observed

\footnotetext{
${ }^{3}$ Such a latent variable may reflect constraints of a central bank, which we do not consider for simplicity of our model.

${ }^{4}$ Such import of low inflation is theoretically grounded as well as empirically documented (see Giavazzi and Giovannini 1989, among others).

${ }^{5}$ By this token it does not address other aspects of anchor currency policies, such as those related to international trade and growth.
} 
phenomena are consistent with our model's predictions, but the model itself is much too simplifying to provide straightforward testable hypotheses.

The paper is organized as follows. In Section 2 we review the post-war developments among G3 currencies and introduce further motivation. In Section 3 we present and analyze the formal theoretical model. Section 4 describes the data and brings empirical extensions to illustrate our point about the quest for exchange rate stability. A brief conclusion follows.

\section{Account of Exchange Rate Developments and Further Motivation}

An anchor currency captures a satellite currency when the latter is tied to the former via some more or lees strict exchange rate regime. Options of such a tie range from a simple peg to managed float with an anchor currency as a reference currency. A "currency capture" is excluded when a satellite currency follows pure float. As the development of exchange rate arrangements is an important issue for the analysis in the paper, we bring a brief account of the relevant points.

In terms of exchange rate arrangements, there has been growing support for abandoning regimes between hard pegs and free floats. In a world of high capital mobility, countries must choose one of the extremes; floating or hard peg. Such a bipolar view is frequently referred to as a "corner solution" or "hollowing out of intermediate regimes." It was initially discussed by Eichengreen (1994); relevant arguments were further provided by Obstfeld and Rogoff (1995), Goldstein (1999), and Eichengreen and Fisher (2001). Proponents of the bipolar view argue that pegs or floats are the only regimes compatible with the current degree of market integration and that countries with high capital mobility should discard intermediate regimes in favor of extreme ones.

The debate on monetary and exchange rate arrangements is not concentrated entirely on Europe or the United States, an impression that may emerge from the stress on euroversus-dollar advances. A comprehensive discussion of a wide range of currency regime changes (actual and potential) around the world is given by Cohen (2004). Further, Bird and Rajan (2002), for example, discuss key aspects of the new Asian financial architecture and focus on the reform of domestic financial systems, exchange rate regimes, and regional liquidity arrangements. Madden, Savage, and McDonald (2000) discuss stabilizing Asia-Pacific exchange rates by establishing a system of pegs, bands or 
target zones around the Japanese yen. ${ }^{6}$ Frieden and Stein (2001) provide a systematic understanding of exchange rate issues by analyzing the political economy of currency policy in Latin America and the Caribbean.

Since the US dollar, Japanese yen, Deutsch mark, and most recently the euro have become the anchor currencies in the post-war period, they also tend to be the most vulnerable to volatility. Exchange rates across the three anchor currencies were particularly volatile in the post-1971 period and our earlier discussion implies the same with respect to the euro. Following the collapse of the Bretton Woods System, attempts to reduce the volatility of exchange rates in economically interconnected Europe led to creation of the "Snake", in 1973 and the European Monetary System (EMS) in 1979. The former Deutsch mark represented the largest weight in a currency basket used to limit volatility of the participating European currencies. Later, economic integration evolved into the Economic and Monetary Union (EMU), the establishment of the European Central Bank, and the adoption of the euro in 1999. Further enlargement of the EMU is expected, since countries that acceded to the EU in 2004 were given no option but to join the EMU at a later date. ${ }^{8}$

Recent developments in the foreign exchange market and the steps of various monetary authorities illustrate phases of instability among the anchor currencies. For example, significant losses in the US dollar's value have formed the basis for complaints that the euro has borne a disproportionate share of the dollar's decline. ${ }^{9}$ Complaints about overvaluation or undervaluation of the US dollar relative to the euro have their predecessors in the context of the Deutsch mark and other currencies under the former European Monetary System (EMS), as well as in past disputes on "fair" parity between the dollar and the yen. Figure 1 illustrates the relationships among key currencies in the post-war period.

\footnotetext{
${ }^{6}$ This strategy requires the compromise of domestic policy autonomy and a symmetric reaction to economic shocks to ensure the lowest cost. The authors suggest that the economic preconditions for a yen bloc are, however, not yet in place.

7 This group of countries, the so-called "Snake", consisted of Germany, the Netherlands, Belgium, and Denmark; it also included France on several occasions. In 1973, these countries fixed their exchange rates with each other while jointly floating against other countries.

${ }^{8}$ For a classic in-depth analysis of the EMS, as well as its relevance for the rest of the world, see Giavazzi and Giovanninni (1989). For a description of European integration around a common currency and for an explanation as to why many of the EU states have agreed to sacrifice their monetary independence, see Overturf (2000).

${ }^{9}$ From 2001 to early 2004 the dollar fell by 33\% against the euro and by $15 \%$ against the Japanese yen.
} 
As we noted earlier, we cannot expect stability in the system of currencies to be attainable. We aim to illustrate this point with the aid of a stylized formal model based on the simple and widely recognized premise that a central bank's objective is price stability. The interest rate, as the main factor in a latent one-dimensional policy instrument, is used to conduct bank policy. The model and motivation for it are described in the next section.

\section{Model and Equilibrium Analysis}

Cohen (1998) introduced the notion of a currency's "authoritative domain" by combining the functional dimension (transactions) as well as the physical dimension (territoriality) of money into "a single amalgam of use and authority." The authoritative domain of an anchor currency expands when the central bank of a satellite currency decides to peg its domestic currency to an anchor currency. In effect, control over the value of such a satellite currency is ceded to a dominating or anchor foreign currency. The authoritative domain of a foreign anchor currency expands with the number and, more specifically, volume of satellite currencies that are tied via various exchange rate regimes to the anchor currency. Under these circumstances, satellite currencies do not have reason to disappear, though their authoritative domain is greatly eroded. Consequently, transactions and their volumes represent an economic transmission mechanism that gives the central banks of anchor currencies control over satellite currencies. These economies of scale are further enhanced because "the currency of a country that has a large share of international output, trade and finance has a natural advantage" (Jeffrey Frankel as quoted in Cohen, 1998, p. 97).

Given this reality of the international geography of money, we build a model of spatial competition among the central banks of anchor currencies in a two-stage game setup. There are $n$ anchor currencies, each attached to one large country (or to a group of countries that form a monetary union). In addition, there is a continuum of satellite countries, each with its own currency. A satellite country is defined by its monetary policy having only a negligible influence on world markets. The policy space of the central banks of the anchor currencies is one-dimensional. This one-dimensional policy space is indeed the result of a set of policy choices, but for simplicity we collapse it into one single variable: the interest rate, which is the dominating policy instrument as well as the most significant loading factor of our formal generalization. Within this policy space, 
there is a range that fulfills the basic goals of the central bank. Normalize this feasible policy space to $[0,1] .^{10}$

The objective of an anchor central bank in our model is price stability. An independent central bank prefers domestic policy autonomy to exchange rate management, as it has no socio-political incentives to produce competitive, stable exchange rates. Its goals are predominantly to achieve low domestic inflation. ${ }^{11}$ Indeed, in reality, usually price stability and, hence, some type of inflation management belongs to the explicit goals of a central bank. Implicitly, central banks may be concerned about economic growth or trade deficit, since these are related to the bank's foreign exchange reserves. Thus, these goals also serve to increase price stability, albeit indirectly. ${ }^{12}$ Central bank positioning within the policy space is done by a latent (unobserved) policy variable resulting from broadly defined relations and constraints which are, for the sake of simplicity, not considered in our setup. Instead, we simplify the composed policy variable by making the interest rate its main factor, which is naturally used for positioning purposes.

Using standard theory, the origin of a monetary base can be inferred from a country's choice of exchange rate regime. If a country favors a floating exchange regime, then the monetary authority has, by definition, full control over its monetary policy, no exchange rate policy, and a monetary base whose origin is entirely domestic. On the other hand, if a country prefers to peg its domestic currency to a foreign one, then the central bank de facto resigns from an independent monetary policy, conducts an explicit exchange rate policy, and has a monetary base of purely foreign origin. ${ }^{13}$ Any exchange rate regime between the two extremes means a different extent of independence in both its monetary

\footnotetext{
${ }^{10}$ Replacing the interval by an open interval does not change the results. Further, given that our policy variable is assumed to primarily reflect the interest rate, our one-dimensional policy space is better characterized as a line and not, for example, as a circle, as a circular policy space would imply that very high and very low interest rates correspond to the same policy. We address generalizations to a multidimensional policy space below.

${ }^{11}$ Baines (2001) documents three trends in the political economy of exchange rate policy in advanced industrialized countries: unprecedented rise in capital mobility, favor of floating exchange rates (at least officially) and need for sound monetary policy, and high levels of central bank independence. These trends result in monetary policy directed at maintaining domestic price stability above all other concerns. In our model we employ price stability as a central bank's objective.

${ }^{12}$ In any event, in our stylized model we restrict attention to the single and arguably dominant motive of price stability. In reality, specific goals vary across central banks but we prefer to keep the model tractable over maximizing its realism. We might actually not lose too much in terms of realism due to our simplification. For example, we do not incorporate (explicitly) trade into our model since both theory and empirics show no effect of the exchange rate system on trade or welfare (see Bacchetta and van Wincoop, 2000).

${ }^{13}$ In this context we can say that an anchor currency "absorbs" the currency of a satellite country.
} 
and exchange rate policies as well as a mixed origin of its monetary base. Hence, by knowing the (true) adopted exchange regime we may identify the amount of domestic money (of a satellite currency) linked to a particular anchor currency via the exchange rate regime, and express this amount in terms of the anchor currency. The combined amounts may be understood as a proxy for the extent of the anchor currency's authoritative domain or, conversely, for the dependency of satellite currencies.

We define the dependencies of satellite currencies on anchor currencies in the context of arguments given by Reinhardt and Rogoff (2004). Based on their categorization of de facto (true) exchange regimes, we are able to trace the preference of satellite currencies' central banks with respect to anchor central banks and, thus, to classify shares of foreign currency holdings. In this way we can proxy for the anchor currency's authoritative domain more precisely than relying on official exchange regime categorization, which often does not reflect reality. Formally, let $C$ be the amount of domestic currency expressed in terms of foreign anchor currencies to which a domestic currency is linked via a particular exchange rate regime, and $c_{i}$ be the part of $C$ expressed in anchor currency $i$ that corresponds to the weight of $i$ in the currency basket. Clearly $\sum_{i=1}^{n} c_{i}=C$. This convenient notation covers all possible cases outlined above:

1) when $n=0$, then $C=0$ and the satellite currency is floating;

2) when $n=1$, then the satellite currency is pegged to an anchor currency; and

3 ) when $n>1$, then the satellite currency is under a currency basket peg regime. ${ }^{14}$

Hence, central banks of anchor currencies attract, through their policy choice, satellite currencies that tie with anchor currencies via exchange rate regimes. Satellite countries have a preference for location in the policy space of the anchor currency to which they link their (satellite) currencies. The most preferred locations of satellite currencies are distributed with respect to a density $f$ on $[0,1]$. Satellite countries' preferences differ because their economic conditions differ, i.e. while some are exclusively interested in price stability, others might prefer a somewhat less restrictive policy in order to stimulate growth.

Our basic assumption is that price stability for a large country $i$ (with an anchor currency) depends on two factors: the policy (interest rate) of the central bank, $x_{i}$, and the

\footnotetext{
${ }^{14}$ More details on the construction of monetary aggregates are given in section 4 in conjunction with our empirical assessment.
} 
share $s_{i}$ of domestic currency, expressed in anchor foreign currency $i$, that is held by satellite countries whose domestic currency is linked via a specific exchange rate regime to anchor currencies. More precisely, the objective function of a central bank is $G_{i}\left(x_{i}, s_{i}\right)$, where $G_{i}$ is a proxy for price stability, and is increasing in $s_{i}$ but decreasing in the absolute difference between its actual policy $x_{i}$ and its preferred policy $p_{i} \cdot{ }^{15}$ Therefore, when choosing its policy, an anchor currency's central bank has to consider not only the direct effect on price stability, but also the indirect effect via the change in the share of satellite currencies linked to it. ${ }^{16}$

We analyze this interaction between the central banks of anchor currencies and those of satellite countries as a two-stage game. In this game, the central banks of anchor currencies first decide simultaneously on their policy, i.e. on their location in the policy space, and then the satellite countries choose their foreign currency holdings. More precisely, the two stages are as follows:

1. The $n$ anchor currency central banks choose simultaneously their policies $x_{1}, \ldots, x_{n}$.

2. After observing $x_{1}, \ldots, x_{n}$ the satellite countries choose their basket of anchor currencies.

Our model resembles the spatial competition model by Eaton and Lipsey (1975), but differs in three respects. First and most importantly, we introduce the preferences of anchor currencies' central banks over their location in the policy space. Second, as will be seen below, satellite countries do not exclusively choose the anchor currency closest to their own preferred policy, but rather a mix of respective closest currencies on both sides such that the weighted average policy of these currencies corresponds to the preferred policy. Finally, central banks can choose identical policies, in which case the linked

\footnotetext{
${ }^{15}$ The objective function $G_{i}$ is increasing in $s_{i}$ since the connection of satellite currencies to an anchor currency decreases volatility in the informal currency area, and hence fosters international trade and further increases stability. Such effects naturally reduce the costs of business activities. Since the economic conditions in the different anchor currency countries differ, they have, not considering the effects of their policy choices on satellite countries' pegs, different preferences with respect to their policy. ${ }^{16}$ Devereux, Shi, and Xu (2004) deliver a model of monetary policy under a US dollar standard and describe how to conduct a monetary policy once an anchor currency rounds up satellite currencies. Their work potentially can motivate our own, as well as lend support to our model which, besides other things, describes how to get to the point when satellite currencies are linked to anchor currencies via foreign exchange standards.
} 
countries choose baskets with equal shares in these currencies. ${ }^{17}$ We show below that two central results of the basic spatial competition model, namely existence of a pure-strategy equilibrium in the case of two anchor currencies, but non-existence of a pure-strategy equilibrium in the case of three anchor currencies, continue to hold if the costs of deviating from the preferred policy $p_{i}$ are not too high and if the preferred policies of central banks of anchor currencies are relatively homogeneous compared to the distribution of preferred policies of satellite countries.

Consider first the behavior of the satellite countries in the second stage. Since their effective interest rate corresponds to the weighted average of the interest rates attached to the currencies in their basket, they aim to peg to a basket such that the weighted average of the interest rates of the anchor currencies in the basket is as close as possible to their preferred policy $l$, because this implies that the basket reflects their own preferred policy as closely as possible. We assume, furthermore, that as a secondary criterion, a satellite country prefers to include in the basket anchor currencies whose policy choice is closer to their own preferred policy (as this might lead to greater stability of the basket). If a satellite country has a choice between two different baskets that have the same weighted average policy, it chooses the basket that minimizes the maximal difference between $l$ and the policies of the anchors included in the basket.

Given the satellite countries' preferences over the baskets they could peg to, their optimal choice will be a mix of the closest anchor currencies, given each possible combination of policies among the anchors. More precisely, as above let $C$ be the amount of domestic currency expressed in terms of foreign anchor currencies to which a domestic currency is linked via a particular exchange rate regime, and $c_{i}$ be the part of $C$ expressed in anchor currency $i$ that corresponds to the weight of $i$ in the currency basket $\left(\sum_{i=1}^{n} c_{i}=C\right)$. Without loss of generality, assume $x_{1} \leq \ldots \leq x_{n}$. If $l \leq x_{1}$ then the country will choose a currency basket consisting only of currency $1, c_{1}=C$; in such a case the currency basket reduces to a simple peg. If $l \geq x_{n}$ then the country will choose $c_{n}=C$. If $x_{i} \leq l \leq x_{i+1}$ then the country will choose a mix of currencies $i$ and $i+1, c_{i}=C \frac{x_{i+1}-l}{x_{i+1}-x_{i}}$, $c_{i+1}=C \frac{l-x_{i}}{x_{i+1}-x_{i}}$. Note that $\left(c_{i} x_{i}+c_{i+1} x_{i+1}\right) / C=l$ and that $c_{i}=C$ if $l=x_{i}$. If $x_{i-1}=x_{i}$ then

\footnotetext{
${ }^{17}$ Such behavior can be observed during periods of post-war development and was a prominent feature of emerging economies during the last two decades of the 20th century.
} 
$c_{i-1}=c_{i}=\frac{C}{2} \frac{x_{i+1}-l}{x_{i+1}-x_{i}} \quad$ and similarly if $\quad x_{i+1}=x_{i+2}$ then $\quad c_{i+1}=c_{i+2}=\frac{C}{2} \frac{l-x_{i}}{x_{i+1}-x_{i}} \quad$ (and correspondingly if more than $2 x$ are identical). ${ }^{18}$ Below, we will consider subgameperfect equilibria, where in each subgame following a choice of policies by the anchor currency countries, satellite countries will choose their best reply, i.e. choose their baskets as above. Thus when we discuss different equilibria below, we will only describe the behavior of the anchor currency countries explicitly.

Let us now turn to the first stage of the game, the anchors' choice of locations in the policy space. Assume for simplicity that $C$ is identical for all satellite countries and normalize $C=1$. Without loss of generality, this can be achieved by replacing the density of satellite countries $f$ by the density of in-foreign-currency-expressed holdings $f^{*}$ with $f^{*}(l)=\frac{f(l) C(l)}{\int_{0}^{1} f(l) C(l) d l}$ for all $l \in[0,1]$, where $C(l)$ denotes the average currency holding of the countries whose preferred location is $l$. Denote by $s_{i}$ the share of currency $i$ of the total in-foreign-currency-expressed holdings by satellite countries.

Each anchor currency's central bank has a preferred policy $p_{i}$. As noted above, the aim of an anchor currency's central bank is to maximize $G_{i}\left(x_{i}, s_{i}\right)$, where $G_{i}$ is assumed to be linear increasing in $s_{i}$ but the costs of deviating from the preferred policy $p_{i}$ (henceforth 'location costs') is convex in the absolute difference. More precisely, let $G_{i}\left(x_{i}, s_{i}\right)=s_{i}-L\left(x_{i}-p_{i}\right)$ with $L(-y)=L(y), \quad L^{\prime}(0)=0$ and $L^{\prime \prime}(y)>0 .{ }^{19}$ Assume furthermore for simplicity that the preferred policies of satellite countries are distributed according to a uniform distribution on $[0,1]$ and that location costs are quadratic, $L(y)=a(y)^{2}$ with $a>0 .{ }^{20}$ Since the leading economies are more alike than the whole spectrum of countries, the preferred policies of central banks of anchor currencies are assumed to be relatively similar compared to the distribution of preferences of satellite currencies' central banks. Furthermore, it appears that small deviations from the preferred policies have a relatively small impact on stability compared to $s_{i}$; hence $a$ is assumed to be small enough such that concerns for location costs do not dominate concerns for the

\footnotetext{
${ }^{18}$ Modern monetary history documents that the number of currencies in a basket usually ranges from 2 to 5. The basket of currencies within the former EMS is an exception due to the institutional setup.

${ }^{19}$ Note that the cost function is the same for all anchor countries; only $p_{i}$ differs.

${ }^{20}$ We will elaborate below on generalizations.
} 
share of currency holdings $s_{i}$.

Proposition 1: Let there be two anchor currencies and let their preferred policies be $p_{1}<p_{2}$. Then

(a) There is an equilibrium $x_{1}=x_{2}=\frac{1}{2}$ if $p_{1} \geq \frac{1}{2}-\frac{1}{4 a}$ and $p_{2} \leq \frac{1}{2}+\frac{1}{4 a}$.

(b) If $p_{2}-p_{1}>\frac{1}{2 a}$ and $\left|1-p_{1}-p_{2}\right| \leq a\left(p_{2}-p_{1}\right)^{2}-\frac{1}{4 a}$, then $\left(x_{1}, x_{2}\right)$ with $x_{1}=p_{1}+\frac{1}{4 a}$ and $x_{2}=p_{2}-\frac{1}{4 a}$ forms an equilibrium.

(c) Otherwise there is no equilibrium in pure strategies.

The proof extends the logic of the basic Hotelling game to the case with location costs. It involves nothing but checking systematically that under the given conditions no central bank of the anchor currencies has an incentive to deviate, while in all other constellations of policies at least one of them does have an incentive to deviate. For details and proof of the Proposition 1, see the Appendix.

While the proof is somewhat tedious, the results are intuitive. Part (a) says that if the preferred policies are close enough to the median of the distribution of small countries, such that marginal location costs are smaller than $1 / 2$ at the median (note that if $x_{1} \neq x_{2}$, the absolute value of the derivative of $s_{i}$ with respect to $x_{i}$ is $1 / 2$ ), then the classical result that both central banks choose the location at the median survives. Obviously, this is the only equilibrium where both central banks choose the same policy since otherwise a marginal deviation would lead to an increase in $s_{i}$ at essentially zero location costs. Part (b) says that if the preferred policies are sufficiently far apart, both central banks will choose policies such that marginal location costs are equal to marginal gains in $s_{i}$, i.e. $1 / 2$. Note that this implies that chosen policies are closer together than the preferred policies. $\left|1-p_{1}-p_{2}\right| \leq a\left(p_{2}-p_{1}\right)^{2}-\frac{1}{4 a}$ ensures that neither of the two banks has an incentive to "pass" the other bank.

For example, if $a=1$ then there is an equilibrium at $\frac{1}{2}$ if $p_{1} \geq \frac{1}{4}$ and $p_{2} \leq \frac{3}{4}$. The range for $p_{1}$ and $p_{2}$ such that $x_{1}=x_{2}=\frac{1}{2}$ is an equilibrium decreases in $a$. Similarly for $a=1$ if $p_{2}-p_{1}>\frac{1}{2}$, there is an equilibrium $x_{1}=p_{1}+\frac{1}{4}, x_{2}=p_{2}-\frac{1}{4}$ as long as $\left|1-p_{1}-p_{2}\right| \leq\left(p_{2}-p_{1}\right)^{2}-\frac{1}{4}$. Thus, in order for such an equilibrium to exist, the 
preferences of central banks of anchor currencies have to be very different, but the range where such an equilibrium exists increases in $a$.

The above logic also applies to more general distributions of the preferred policies of satellite countries and to more general convex location costs. In particular, if $L$ is sufficiently small and the preferred policies of the two central banks of anchor currencies are relatively close to the median of $f$, then there is an equilibrium where both choose policies equal to the median. If the preferred policies are rather different and location costs are high, then there is an equilibrium where they choose different policies (which are, however, closer together than their preferred policies). In the first case, where concerns for location costs are dominated by concerns for the share of satellite countries, the minimal differentiation result holds, whereas if location costs dominate concerns for shares in satellite countries, there is an equilibrium with unequal policies.

Note that since conditions (a) and (b) are mutually exclusive, the pure-strategy equilibrium (if it exists) is unique. Hence, in a finitely repeated game the equilibrium play will be repeated and the situation is stable in the sense that the policies of the two anchor currencies are stable over time and that satellite countries do not change their exchange rate regimes. In the case of an equilibrium of type (a) the policies will change if, due to external shocks, the preferred policies of the satellite countries shift. They will, however, change in a parallel fashion provided that the shift is not too radical, because the equilibrium policies will stay at the median as long as the condition in (a) remains fulfilled. The policies will, however, not change if the preferred policies of the central banks of anchor currencies shift as long as condition (a) holds. But they will shift if the equilibrium is of type (b). Furthermore, if the preferred policies of the central banks of anchor currencies move closer together over time, we can move from an equilibrium of type (b) to one of type (a) (if preferred policies are relatively symmetric to the median of $f$ ) or to non-existence of a pure-strategy equilibrium (if they are highly asymmetric). In an infinitely repeated game, Folk-theorem arguments imply that we get additional equilibria. Repeated play of the stage-game equilibrium is, however, also one equilibrium of the infinitely repeated game such that if the conditions in (a) or (b) hold, a stable pattern would be one equilibrium (and the only one that does not require any punishment threats to be stabilized). 
Proposition 2: Let $n=3$ and $p_{1}<p_{2}<p_{3}$.

(a) If

(1) $\quad p_{2}-p_{1} \geq \frac{1}{4 a}$,

(2) $\quad p_{3}-p_{2} \geq \frac{1}{4 a}$,

(3) $\quad \max \left\{p_{1}+\frac{p_{2}}{2}-\frac{p_{3}}{2}+\frac{7}{16 a},-\frac{p_{1}}{2}-p_{2}+\frac{p_{3}}{2}-\frac{3}{16 a}\right\} \leq a\left(p_{2}-p_{1}\right)^{2}$,

$$
\max \left\{1+\frac{p_{1}}{2}-\frac{p_{2}}{2}-p_{3}+\frac{7}{16 a},-1-\frac{p_{1}}{2}+p_{2}+\frac{p_{3}}{2}-\frac{3}{16 a}\right\} \leq a\left(p_{3}-p_{2}\right)^{2},
$$

then $\left(p_{1}+\frac{1}{4 a}, p_{2}, p_{3}-\frac{1}{4 a}\right)$ is an equilibrium.

(b) Let $x_{3}=p_{3}-\frac{1}{4 a}$ and $x_{1}=\frac{x_{3}}{3}$. If $p_{2} \leq x_{1} \leq p_{1}+\frac{1}{4 a}$ and

(5) $1 \leq \frac{8}{9} p_{3}+\frac{8}{9} a p_{3}^{2}-\frac{5}{18 a}+\frac{p_{2}}{3}-\frac{4}{3} a p_{2} p_{3}$,

then $\left(x_{1}, x_{1}, x_{3}\right)$ is an equilibrium.

(c) Let $x_{1}=p_{1}+\frac{1}{4 a}$ and $x_{3}=\frac{x_{1}+2}{3}$. If $p_{3}-\frac{1}{4 a} \leq x_{3} \leq p_{2}$ and

(6) $2 \geq 8 p_{1}+4 a p_{1}-8 a p_{1}^{2}+4 a+\frac{5}{2 a}+3 p_{2}-12 a p_{2}+12 a p_{2} p_{1}$,

then $\left(x_{1}, x_{3}, x_{3}\right)$ is an equilibrium.

This is just a mirror image of case (b).

(d) Otherwise there is no pure-strategy equilibrium.

As for proposition 1, the proof is somewhat tedious but involves only checking systematically that given the above conditions, no central bank has an incentive to deviate, while in all other constellations of policies, at least one bank has an incentive to deviate. For details and proof of the Proposition 2, see the Appendix. While more technical assumptions are needed here than in Proposition 1 to ensure that in the given equilibrium no bank would like to deviate to a position just marginally beyond the position of one of the other banks, the main results are again intuitive. In case (a), conditions (1) and (2) ensure that if banks 1 and 3 move to the positions where marginal location costs are equal to the marginal gains in the share (i.e. $1 / 2$ ), bank 1 is still to the left of bank 2 and bank 3 to the right of bank 2. Since bank 2 cannot change its share by moving between banks 1 and 3, the only such constellation that is an equilibrium is that bank 2 chooses its preferred policy. For case (b) note that independent of $a$, a necessary requirement is $\quad p_{3}-p_{2}=x_{3}-p_{2}+\frac{1}{4 a} \geq x_{3}-x_{1}+\frac{1}{4 a}=2 x_{1}+\frac{1}{4 a} \geq 2 p_{2}+\frac{1}{4 a}, \quad$ whereas $p_{2}-p_{1} \leq \frac{1}{4 a}$, hence the preferences of bank 2 are much closer to those of bank 1 than to 
those of bank 3. A parallel requirement applies to case (c). Thus cases (b) and (c) involve situations where two banks whose preferred policies are relatively close, will choose the same policy (resembling the formation of a monetary (policy) union) while the third bank whose preferred policy is very different, will choose a policy such that its marginal location costs are equal to the marginal gain in the share (i.e. $1 / 2$ ).

Hence existence of a pure strategy equilibrium requires that at least one central bank has preferences very different from the other central banks. Note in particular that there is no equilibrium where all three banks choose the same location. In this case, they would all receive $s_{i}=1 / 3$, but a marginal deviation would allow a bank to capture at least $s_{i}=1 / 2$ at a negligible increase in location costs.

Let us consider again the case $a=1$ for illustration. Conditions (1) and (2) imply that an equilibrium of type (a) only exists if $p_{3}-p_{2} \geq \frac{1}{4}$ and $p_{2}-p_{1} \geq \frac{1}{4}$, that is, if the preferred policies of central banks of anchor currencies are highly heterogeneous. Conditions (3) and (4) are even more restrictive, requiring for example, that for $p_{1}=0$ and $p_{2}=\frac{1}{2}$ that $p_{3} \geq \frac{\sqrt{15}}{4}$ or that for $p_{2}=\frac{1}{2}$ and $p_{3}=1$ that $p_{1} \leq 1-\frac{\sqrt{15}}{4}$. The range of parameters such that an equilibrium of type (a) exists increases in $a$. An equilibrium of type (b) only exists if the preferences of banks 1 and 2 are relatively similar and those of bank 3 are quite different. In particular, if $a=1$, then even for $p_{3}=1$ and, hence, $x_{3}=\frac{3}{4}$, $p_{1}<p_{2} \leq \frac{1}{4}$ is necessary. Hence, an equilibrium in pure strategies exists only if preferences are highly heterogeneous or if location costs are very high.

If, as we argued above, central banks of anchor currencies are relatively homogeneous in their preferences compared to satellite countries and if the weight they attach to satellite countries being linked to their currency is large compared to the costs of marginal deviations from the preferred policy, there is no equilibrium in pure strategies with $n=3$. With $n=2$, however, there is an equilibrium where both central banks of anchor currencies choose a policy at the median of $f$, i.e. the basic results of the standard spatial competition model still hold.

The qualitative results of proposition 2 should also hold for more general convex cost functions and more general distributions of preferences of satellite countries. ${ }^{21}$ In

\footnotetext{
${ }^{21}$ In the latter case, $x_{2}=p_{2}$ would in general not hold any more in type (a) equilibrium, because density $f$
} 
particular, if central banks' preferences are relatively homogeneous compared to the preferences of satellite countries and location costs are not excessively high, there is no equilibrium in pure strategies. The logic is the same as in the standard spatial competition model: banks 1 and 3 would like to choose locations close to $x_{2}$. In that case $s_{2}$ would be small, but bank 2 could increase $s_{2}$ at only a small increase in location costs by deviating to $x_{1}-\varepsilon$ or $x_{3}+\varepsilon$.

In a (finitely) repeated game the non-existence of a pure-strategy equilibrium means that the actual choices of central banks in period $t$ do not form an equilibrium. Therefore, at least one central bank would like to change its policy. Hence, the configuration of locations of central banks of anchor currencies will change from period $t$ to $t+1$, even without external shocks and, moreover, not in a parallel fashion.

In other words, if there is no pure-strategy equilibrium there is only a mixed-strategy equilibrium and naturally the mixed strategies will (in general) yield different realizations and hence different locations of anchor currencies in each period. Thus we would expect fluctuating policies of the anchor currencies to follow a random pattern. As a consequence, the currency baskets of at least some of the satellite countries will also change from period to period. $^{22}$

The difference between the cases $n=2$ and $n=3$ can be summarized as follows. If preferences of central banks of anchor currencies are highly heterogeneous or location costs are very high, then for both $n=2$ and $n=3$ a pure-strategy equilibrium exists where central banks choose different policies. But if, as we assume, preferences of central banks of anchor currencies are relatively similar compared to the distribution of satellite countries' preferences and location costs are not very high, then the result of the model without location costs survives, namely that for $n=2$ there is an equilibrium where both central banks choose a policy at the median of the distribution of satellite countries' preferences, and if $n=3$, then there is no equilibrium in pure strategies. In the latter case, the implementation of mixed-strategy equilibrium policies would follow a random pattern. $^{23}$

\footnotetext{
is not constant and hence $s_{2}$ is not the same for all $x_{2}$ with $x_{1}<x_{2}<x_{3}$.

${ }^{22}$ Such behavior can be observed in the case of emerging economies in our sample.

${ }^{23}$ Our results indicating stability with two anchor currencies are also broadly in line with numerous theoretical models of foreign exchange trading that use a two currency framework (see Matsuyama,
} 
Although general results for $n>3$ can be derived by a similar extension of Eaton and Lipsey (1975), this work is beyond the scope of this paper. Eaton and Lipsey (1975) also show that the results are quite different for a higher dimensional choice space. This fact would most likely carry over to our model if we extended it to a multi-dimensional policy space. However, even if we considered a higher-dimensional policy space, our model would always be a substantial simplification. Hence, our results can only be an illustration of the possible impact of changes in the number of anchor currencies. Therefore, we prefer to adhere to the comparatively simple one-dimensional version of the model.

Our results also give insight into the notion of a currency's authoritative domain as explicated by Cohen (1998). We extend his arguments by showing that the existence of equilibrium strongly depends on the number of competing anchor currencies.

\section{Data and Statistical Inference}

\subsection{Data and Quantitative Evidence}

We collected data on the exchange rates of domestic currencies with respect to the US dollar, the Deutsch mark/ECU/euro, and the Japanese yen. Furthermore, we assembled data on monetary aggregates (in terms of M2), short-term interest rates, type of exchange rate regimes, inflation and aggregate output for 30 OECD countries plus Russia. Because of their economic capacity and derived amount of monetary aggregate used, we consider the OECD countries as a proxy for the world. ${ }^{24}$ Short-term interest rates are defined as three-month money market rates, or rates on similar financial instruments. The span of our yearly data is 1963 to 2004, with the exception of emerging economies where meaningful data are available only from the mid-1980s. All data were assembled from OECD Economic Outlook statistics, IMF International Financial Statistics and, for particular missing data, from the central banks and finance ministries of the respective countries. $^{25}$

Kiyotaki, and Matsui, 1993; Zhou, 1997 among others). Moreover, the non-existence of equilibrium in pure strategies in the case of three currencies corresponds to the results of Rey (2001), where the three-country model of the world economy has three partial and three total equilibria, where each currency can be the vehicle.

${ }^{24}$ Because of this, we do not incorporate into our sample a number of satellite countries.

${ }^{25}$ Due to data inconsistencies we do not cover the 1950s in our analysis. This exclusion does not constitute a deficiency since the Bretton Woods System was firmly in place at that time and no repositioning implied by our model could take place. 
We construct the sums of monetary aggregates (M2) of satellite currencies to anchor currencies based on the description of de facto (true) exchange regimes provided in Reinhardt and Rogoff (2004). In accord with our model in section 3, we define $C$ as the amount of domestic (satellite) currency expressed in terms of foreign anchor currencies to which a domestic currency is linked via the particular exchange rate regime; $c_{i}$ is the part of $C$ expressed in anchor currency $i$ that corresponds to the weight of $i$ in the currency basket $\left(\sum_{i=1}^{n} c_{i}=C\right) \cdot{ }^{26}$ This convenient notation covers all possible cases that are of interest: when $n=0$, then $C=0$ and the satellite currency is floating; when $n=1$, then the satellite currency is pegged to an anchor currency, and when $n>1$, then the satellite currency is under a currency basket peg regime. If a country favors, for instance, a currency basket peg, then the weights of currencies in a basket are used to determine the importance of anchor currencies with respect to satellite currency holdings. Since currencies in a basket usually represent those most frequently used in the conduct of international trade or international monetary operations of a particular country, such an approach is fully justified.

In sum, we specify the amount of a satellite currency linked to a particular anchor currency via the exchange rate regime, and express this amount in terms of such anchor currency. We believe that the combined amounts may be understood as a reasonable proxy for the extent of an anchor currency's authoritative domain, despite the fact that "the data simply do not exist to accurately report all cross-border use of currencies, let alone more subtle relationships" as Cohen (1998, p. 24) accurately notes. We trust that our construction is a realistic way to operationalize the concept of the authoritative domain.

The overall situation with respect to developments of monetary aggregates from the 1960s to 2004 is captured in Figures 2-5. They illustrate how the share of monetary aggregate linked to an anchor currency as well as the share of countries linked through their exchange rate regimes to anchor currencies evolved over time. In accordance with historical developments we see a massive shift away from the US dollar after the collapse

\footnotetext{
${ }^{26}$ Technically, $C$ should also include foreign exchange reserves of central banks of satellite currencies held in anchor currencies. However, since those foreign exchange reserves consist of currencies already issued by the central banks of anchor currencies, we cannot consider them. Aside from this, the structure of foreign exchange reserves held usually reflects the weights of the anchor currencies within the exchange rate regime.
} 
of the Bretton Woods System, and a proportionally pronounced gain in Europe. While the share of currencies linked to the US dollar stabilized in the late 1980s, the European currency has been steadily solidifying its share. The share of currencies not linked to any anchor currency has never exceeded 30 per cent and meanders over time; the share of monetary aggregate of these countries tends to be negligible. The Japanese yen has a significant share of money linked to it, hovering around 30 per cent of the total.

Figure 6 presents the total amount of monetary aggregate of all considered currencies divided into three groups in terms of exchange rate regime link. Currencies are linked either to the US dollar, to the Deutsch mark/ECU/euro, or to the Japanese yen. In the context of our model the US dollar clearly dominates from the 1960s to 1971-1973. This is when the number of anchor currencies is just one; $n=1$. Period 1971-1979 represents a transition after the Bretton Woods System collapsed. We see a departure from state $n=1$ towards $n>1$. During this period there exist no obvious candidates that would firmly establish a situation of two anchor currencies in which $n=2$. Developments after 1979 illustrate the lack of two dominating currencies, since the amount of monetary aggregate of currencies linked neither to the US dollar nor to the Deutsch mark/ECU/euro is substantial. Most, but not all, of the non-linked aggregate originates in Japan. Hence, the post-1979 period represents a situation in which, in the framework of our model, unquestionably $n>2$ and no pure-strategy equilibrium exists.

Short-term interest rates, plotted in Figure 7, allow us to detect changes in the positioning of the central banks of anchor currencies in one-dimensional space. Shortterm interest rates vary extensively and do not move in a parallel fashion. The differences among the short-term rates are relatively small and the differential between Japanese and US/European rates becomes slightly more pronounced only in the 1990s. Such behavior is consistent with our model specification, which assumes that central banks use a latent variable (with the largest loading factor being associated with the interest rate) for

positioning purposes in the one-dimensional policy space. Evidence shows that interest rates interact over time; disparities due to central banks altering the interest rate have been adjusted quickly.

\subsection{Empirical Econometrics and Statistical Inference}

In our model we assume that the central bank of an anchor currency uses the interest rate 
as a major factor forming the latent (unknown) policy instrument that is used for positioning purposes within the one-dimensional space. Our model predicts that a change in this instrument ultimately leads to a change in the choice of satellite countries with respect to their ties to anchor currencies. To provide an empirical context to our model we formulate the specification in the form of a system of equations, which directly corresponds to the two stages of the model.

In the first stage of the model a central bank is positioning itself within the onedimensional space by setting an interest rate. The first equation is formulated in the spirit of the policy rules suggested by Taylor (1993), Clarida, Gali and Gertler (2000) or Woodford (2001) in which interest rate is determined based on information derived from inflation and aggregate output. ${ }^{27}$ In our case we formulate the specification in which change in interest rate $\left(\Delta s r_{t}^{i}\right)$ is a function of inflation and growth of the aggregate output and its lagged values:

$$
\Delta s r_{t}^{i}=c^{i}+\beta_{1} \pi_{t}^{i}+\beta_{2} \pi_{t-1}^{i}+\gamma_{1} y_{t}^{i}+\gamma_{2} y_{t-1}^{i}+u_{t} .
$$

Here $c$ is a constant, $\pi_{t}$ is inflation in country $i$, and $y_{t}$ is aggregate output growth rate in country $i$. The specification is in line with the objective of an anchor currency's central bank in our model, which is price stability. ${ }^{28}$

The second equation captures the change in the total amount of monetary aggregate with respect to changes in interest rates. This is a direct representation of the second stage of the model, when the satellite currencies adjust their ties to anchor currencies. Thus we formulate the following model:

$$
\Delta M_{t}^{i}=\alpha_{1} \Delta s r_{t-1}^{U S}+\alpha_{2} \Delta s r_{t-1}^{E U}+\alpha_{3} \Delta s r_{t-1}^{J P}+\varepsilon_{t},
$$

where the left-hand, explained, variable is the change in the (relative) amount of money expressed in the anchor currency $\left(\Delta M_{t}^{i}\right)$; it is measured as relative money in terms of the percentage of the total "world" monetary aggregate. ${ }^{29}$ This amount of money contains

\footnotetext{
${ }^{27}$ Taylor (1993) suggested feedback policy rule while Clarida, Gali and Gertler (2000) argued for a forward looking rule. Woodford (2001) incorporated into the monetary policy model a feedback rule with target values.

${ }^{28}$ Using specification (1) without lags yields results that are not materially different when lags are included. Based on a formal test we opt to use less parsimonious model.

${ }^{29} \mathrm{~A}$ measure of the relative amount of money is used because in our stylized model we assume a world in which all satellite currencies are tied to anchor currencies. Since in reality (condensed in the data) some currencies are occasionally not tied to an anchor currency, we need to re-scale the total monetary aggregate and work with percentage proportions rather than absolute amounts.
} 
monetary aggregates of the satellite currencies expressed in an anchor currency (via exchange rate) plus the aggregate of the monetary currency itself. As in (1), $\Delta s r_{t}^{i}$ represents the change in interest rate. The change in the amount of total money represents the second stage of the model, when the satellite currencies adjust their ties to anchor currencies.

From econometrical point of view an issue of endogeneity of interest rate with respect to monetary aggregate arises. The endogeneity may hamper estimates from specification (2) if it was estimated directly. Our two equation approach fortunately allows to successfully dealing with the endogeneity issue. Specification (1) actually employs inflation and output growth along with its lagged values and constant as instrumental variables and as such it yields predicted values for the interest rate $\left(u_{t}\right)$. Therefore, we use these predicted values, instead of interest rates, when estimating (2) and this way we avoid the endogeneity problem. The instrumental variables pass the formal Sargan-Wu, Hansen $\mathrm{J}$ and Bassman tests of overidentifying restrictions at the $1 \%$ test level and in this sense they qualify as valid instruments.

As for the estimation technique, we estimate the system of equations by employing the generalized method of moments (GMM) with instruments described above. When employing the GMM we use a moving window approach for the following reason. As noted earlier, the time from the 1950s to the present can be divided into three periods: A general tie with the US dollar during the Bretton Woods era, followed by a period of general floating with a few formal arrangements in force that was later replaced by the tripolar currency world. When we again observe Figures 6-7 depicting the evolution of interest rates and monetary aggregates, we witness unstable development with structural breaks that should be accounted for by using an appropriate methodology. ${ }^{30}$ To overcome the time-varying nature of the data, we adopt the rolling estimate approach of Bannerjee, Lumsdain and Stock (1992). We form a moving window that is a constant (15-year) fraction of the full sample and that rolls through the sample. Use of rolling windows effectively allows for possible structural instability, and we employ them in a manner similar to that of Swanson (1998).

To sum, in our study we use rolling 15-year fixed windows (samples) of data to

\footnotetext{
${ }^{30}$ Granger (1996) points out that structural instability may be the most important problem facing forecasters today.
} 
estimate the relationship between the monetary aggregate of an anchor currency and three key interest rates. ${ }^{31}$ By taking this approach we make allowances for that the system may be evolving over time, and we account for potential sub-sample instability. We estimate our model for the three anchor currencies using the sequence of the moving windows over the whole span of data. Coefficient estimates are presented in Tables 1-3; they shed light on the stability of coefficients over time.

More relevant is how the fit of our specification evolves over time, though. The fit is measured by $R^{2}$ and is presented in Figure 8 . Degree of the fit suggests how much of the positioning (of the anchor central banks) and regrouping among the satellite currencies with respect to anchor ones took place. Recall that the central banks of the anchor currencies use a latent variable proxied by the short-term interest rate for their repositioning and that this process is dependent on exchange rate arrangements. Therefore, we should expect the fit of our model to be low during the Bretton Woods era since, by definition, no changes in ties to the dollar were possible. We should also expect a low fit during the period of general float since the former anchor was lost; some arrangements began to emerge but no firm structures were yet established as a general principle. With the emergence of the European Monetary System, its later transformation to the Economic and Monetary Union, and the increased strength of the Japanese economy, changes in aggregate measures of money should better reflect the repositioning process and the fit of the model should increase.

The above hypotheses are confronted with the actual fit of the specification (2) presented in Figure 8. We do witness a very low fit of the model during the first period until the collapse of the Bretton Woods system, a visible increase of the fit during the period of a general float, and a dramatic increase in 1979 (inception of the EMS). The magnitude of the fit during all three periods naturally differs for the three currencies. The fit during the last period, and especially since the mid 1980s, is a very good result for the model specified in differences $(20-40 \%$ for the DEM/ECU/euro-linked currencies, 30$50 \%$ for the yen-linked currencies, and $10-20 \%$ for the dollar-linked currencies). Further,

\footnotetext{
${ }^{31}$ As a robust check we employ a wider moving window (using 20 years instead of 15) and we also impose restriction that IV variables are used only within the framework of the same country; e.g US output growth and inflation are used to predict US interest rate changes only and similarly for Europe and Japan. The results are robust with respect to these changes and are available upon a request.

In a similar spirit to our approach, rolling estimates were recently applied by Bovi (2005), Patel and Shoesmith (2004), Andreou and Ghysels (2002), Smith and Taylor (2001), and Smith (2000).
} 
the fit of the model is driven by the interest rate of an anchor currency as well as by the interest rates of its competitors, whose influence on the model's fit is remarkable and confirms that repositioning takes place according to the two-stage game model.

In sum, the fit of our specification is high during the period when repositioning of the central banks could effectively take place and is low when it could not (Bretton Woods' peg followed by a general float). In other words, we see an inverted-U shaped curve of the fit after the collapse of the Bretton Woods System, when positioning could take place. The expected pattern of the inverted-U shape is present for the yen and the euro. In the case of the dollar, the inverted-U shape is not clearly present because the fit is below any reasonable level of significance; nevertheless, this does not disprove that positioning is taking place. These results are fully consistent with and support the predictions of our theoretical model concerning the behavior of satellite countries. ${ }^{32}$

Our results have provocative implications with respect to recent developments. As the euro has gained in value against the dollar, central banks in Japan, China, and other Asian countries have bought dollars to hold down the value of their own currencies. The total reserves of the four largest Asian economies - China, Japan, South Korea, and Taiwan have more than doubled over the 2001-2003 period and reached 1.5 trillion US dollars, most of it held in American government securities. China itself, until recently (mid2005), kept its currency tightly pegged to the US dollar, which was greatly upsetting nondollar allied Europe. ${ }^{33}$ The European Union appealed to China to let its currency float and to Japan to discontinue its interventions on the yen-dollar market. The EU's rationale behind these appeals was to enhance stability among the exchange rates of the anchor currencies. Our conclusions would indicate just the opposite. In fact, if China kept its link to the dollar and Japan pegged the yen in some way, our model predicts that the overall situation would lean towards a two-currency equilibrium. ${ }^{34}$ China's recent move of

\footnotetext{
${ }^{32}$ When we extend the exposition one step further, our model offers an explanation why Japan is not simply monetizing its debt: according to our model, if they did, one would expect them to lose pegged small currencies, which is bad.

${ }^{33}$ China has kept its currency, the yuan, virtually fixed at 8.28 CNY/USD for the last eleven years. China's central bank adjusted the yuan's value to $8.11 \mathrm{CNY/USD}$ on July 21, 2005 and announced that it would manage it by reference to the basket of currencies of its main trading partners. The composition of the basket was revealed on August 10, 2005: it is dominated by the U.S. dollar, the euro, the Japanese yen and the South Korean won, and also contains the Australian, Canadian and Singapore dollars, the British pound, the Malaysian ringgit, the Russian rouble and the Thai baht. It is estimated (Deutsche Bank) that the US dollar is the largest component of the basket, with a 30 percent weighting. The euro and yen likely take up 20 percent each and the won 10 percent.

${ }^{34}$ This is in line with recent arguments made by McKinnon (2004) and McKinnon and Schnabl (2004).
} 
pegging its currency to a currency basket represented most heavily by the dollar, euro, and yen maintains the status quo in terms of our model's predictions.

\section{Concluding remarks}

In this paper we build a spatial competition model in a two-stage game setup to assess whether stability among the world's leading currencies is attainable. We conclude that a stable equilibrium among the existing anchor currencies is not likely to be achieved under existing monetary arrangements. We show that although a stable equilibrium of exchange rates can arise in the case of two anchor currencies, instability is a prominent feature in the case of three anchor currencies. While the model naturally is a substantial simplification of reality, in this stylized world we hint at the right number of anchor currencies. Outside this stylized world our findings might still hold, but different factors may influence the stability. One issue our model does not address is why a specific number of anchor currencies might exist in the first place. A more general model would endogenize the number of anchor currencies.

We support the assumptions and implications of our model with both quantitative evidence and formal statistical inference. Our empirical results back up the predictions of our theoretical model concerning the behavior of satellite countries. We document large changes in the extent of the authoritative domain of anchor currencies as satellite currencies altered their ties to anchor currencies over time. Implicitly, we witness how the monetary world has changed during the past four decades.

Since firms, traders, and countries currently recognize three anchor currencies and their economic behavior reflects this, we may expect disagreement on overvaluation or undervaluation of certain currencies to continue. Despite the highly stylized character of our model, it provides clear predictions that are corroborated by empirical evidence. The future will tell. 


\section{References}

Andreou, Elena and Ghysels Eric. 2002. Rolling-Sample Volatility Estimators: Some New Theoretical, Simulation, and Empirical Results. Journal of Business and Economic Statistics, 20(3): 363-76

Bacchetta, Philippe and van Wincoop, Eric. 2000. Does Exchange-Rate Stability Increase Trade and Welfare? American Economic Review, 90(5): 1093-1109.

Baines, Adam C. 2001. Capital mobility, perspectives and central bank independence: Exchange rate policy since 1945. Policy Sciences, 34: 171-193.

Banerjee A., R. Lumsdaine and J. Stock. 1992. Recursive and Sequential Tests of the Unit-Root and Trend-Break Hypotheses: Theory and International Evidence, Journal of Business and Economic Statistics, 10(3): 271-287

Bird, Graham and Ramkishen S. Rajan. 2002. The evolving Asian financial architecture. Essays in International Economics, no. 226. Princeton: Princeton University, Department of Economics, International Economics Section.

Bovi, Maurizio. 2005. Globalization vs. Europeanization: A Business Cycles Race. Oxford Bulletin of Economics and Statistics, 67(3): 331-345.

Clarida, Richard, Jordi Gali, Mark Gertler, 2000. Monetary Policy Rules and Macroeconomic Stability: Evidence and Some Theory. Quarterly Journal of Economics 115(1): 147-180.

Cohen, Benjamin J. 2004. The Future of Money. Princeton University Press.

Cohen, Benjamin J. 1998. The Geography of Money. Ithaca: Cornell University Press.

Devereux, Michael, B., Shi Kang, and Xu Juanyi. 2004. Global Monetary Policy under a Dollar Standard. CEPR Discussion Paper No. 4317.

Eaton, B. Curtis and Richard G. Lipsey. 1975. The Principle of Minimum Differentiation Reconsidered: Some New Developments in the Theory of Spatial Competition. Review of Economic Studies, 42(1), pp. 27-49.

Eichengreen, B., 1994, International Monetary Arrangements for the 21st Century (Washington: Brookings Institution).

Eichengreen, B., and S. Fischer, 2001, Exchange Rate Regimes: Is the Bipolar View Correct?, Distinguished Lecture on the Economics in Government, Journal of Economic Perspectives 15(2), 3-24.

Frieden, Jeffry and Ernesto Stein (eds.) 2001. The currency game: Exchange rate politics in Latin America. Washington, D.C.: Inter-American Development Bank; distributed by Johns Hopkins University Press, Baltimore. 
Giavazzi, Francesco and Alberto Giovannini. 1989. Limited exchange rate flexibility: The European monetary system. Cambridge, Mass. and London: MIT Press, 1989

Goldstein, M., 1999, Safeguarding Prosperity in a Global Financial System: the Future International Financial Architecture (Washington: Institute for International Economics).

Granger, C.W.J., 1996. Can we improve the perceived quality of economic forecasts? Journal of Applied Econometrics 11, 455-473.

Hotelling, Harold. 1929. Stability in Competition, Economic Journal, 39, pp. 41-57.

Madden, Gary, Scott Savage, and Andrew McDonald. 2000. Assessing the Economic Preconditions for a Yen Bloc. Australian Economic Papers, 39(1): 25-32.

Matsuyama, Kiminori, Nobuhiro Kiyotaki, and Akihiko Matsui. 1993. Toward a Theory of International Currency, Review of Economic Studies, 60(2): 283-307.

McKinnon, Ronald. 2004. The East Asian Dollar Standard. China Economic Review, 15(3): $325-30$

McKinnon, Ronald and Schnabl, Gunther. 2004 The East Asian Dollar Standard, Fear of Floating, and Original Sin. Review of Development Economics, 8(3): 331-60.

Obstfeld, M. and K. Rogoff, 1995, The Mirage of Fixed Exchange Rates, Journal of Economic Perspectives 9(4), 73-96.

Overturf, Stephen-Frank. 2000. Money and European Union. New York: St. Martin's Press.

Patel, Ajay and Shoesmith, Gary L. 2004. Term Structure Linkages Surrounding the Plaza and Louvre Accords: Evidence from Euro-Rates and Long-Memory Components. Journal of Banking and Finance, 28(9): 2051-75.

Rey, Helene. 2001. International Trade and Currency Exchange, Review of Economic Studies, 68(2): 443-64

Reinhart, Carmen and Kenneth Rogoff. 2004. Modern history of exchange rate arrangements: A reinterpretation. Quarterly Journal of Economics, 119(1): 1-48.

Smith, Richard J., Taylor, A.M. Robert. 2001. Recursive and Rolling Regression-Based Tests of the Seasonal Unit Root Hypothesis. Journal of Econometrics, 105(2): 309-36.

Smith, Michael. 2000. Modeling and Short-term Forecasting of New South Wales Electricity System Load. Journal of Business and Economic Statistics, 18(4): 465-78

Swanson, N.R. 1998. Money and Output Viewed Through a Rolling Window. Journal of Monetary Economics, 41, 455-473. 
Taylor, John B., 1993. Discretion Versus Policy Rules in Practice, Carnegie-Rochester Conference Series on Public Policy 39: 195-214.

Woodford, Michael, 2001. The Taylor Rule and Optimal Monetary Policy, American Economic Review 91(2): 232-237.

Zhou, Ruilin. 1997. Currency Exchange in a Random Search Model, Review of Economic Studies, 64(2): 289-310. 
Figure 1. Exchange Rate Deviations. (March $1973=100$ )

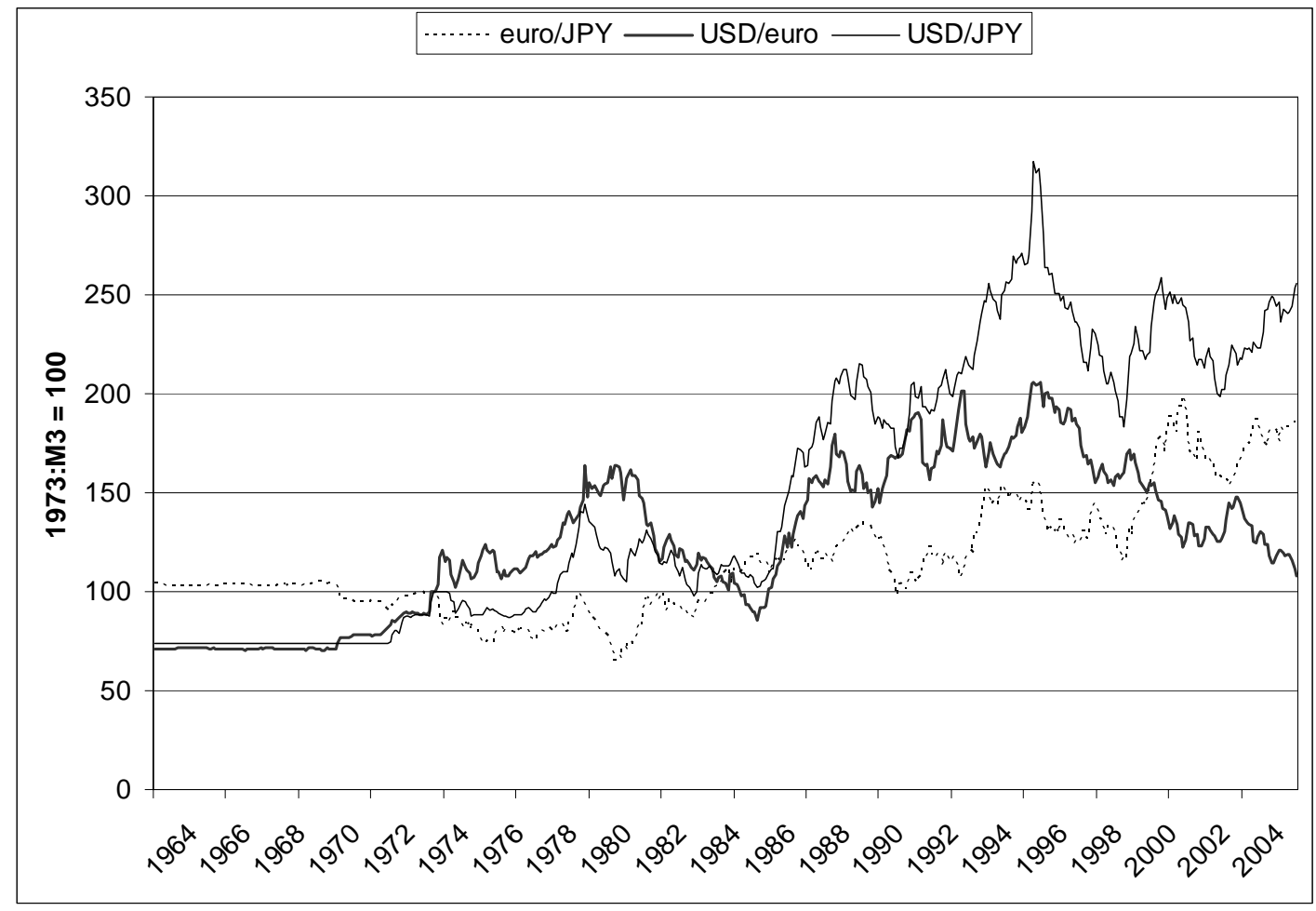

Note: euro refers to euro from 1999 onwards and to DEM and ECU prior to this date. Official fixed parities are used to calculate respective exchange rate. Since the figure is in deviations, it doesn't matter whether DEM, ECU, or euro is used as a common denominator.

Figure 2. Inter-temporal Relative Share of Money and Countries Linked to the US Dollar

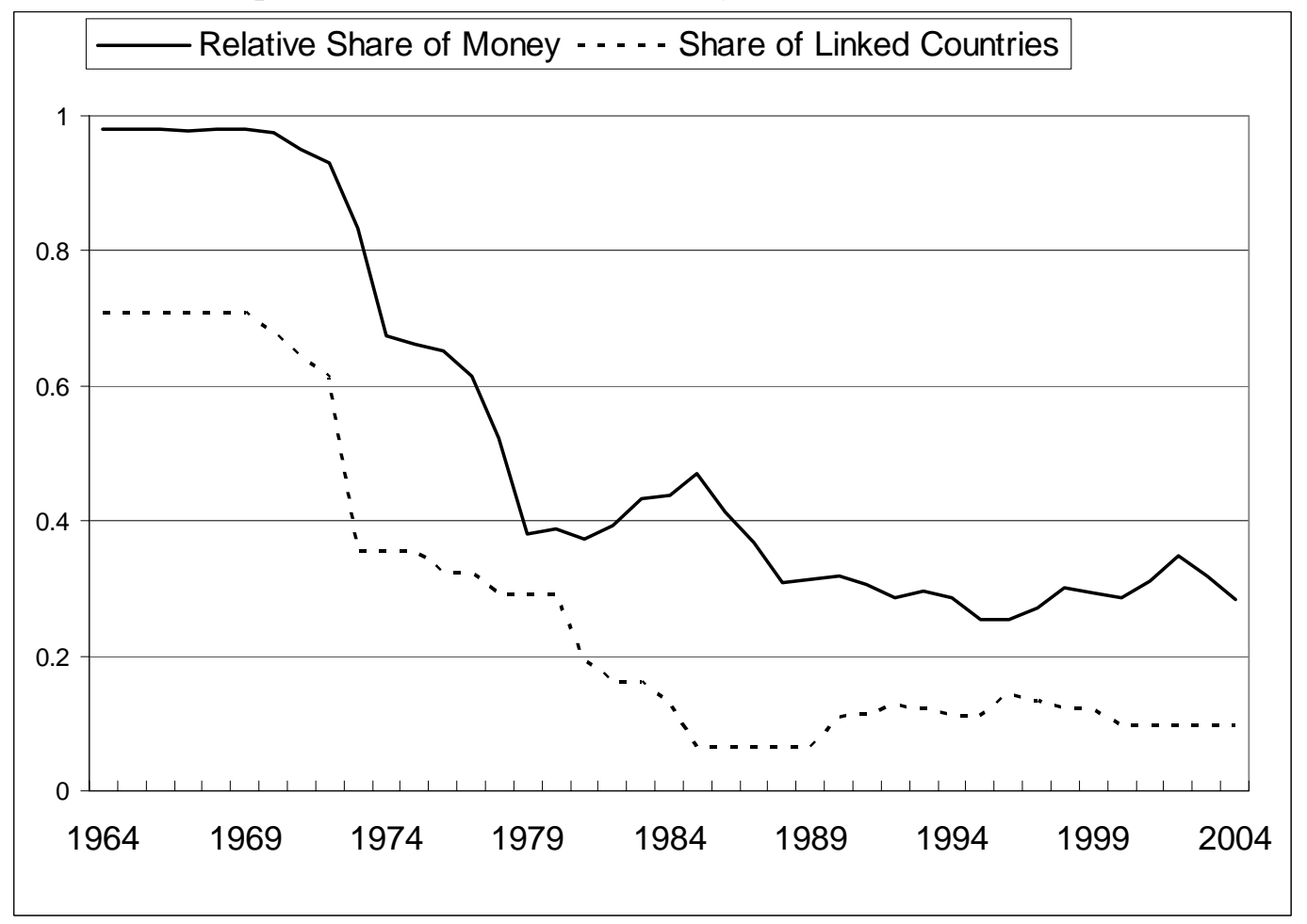


Figure 3. Inter-temporal Relative Share of Money and Countries Linked to the DEM/ECU/euro

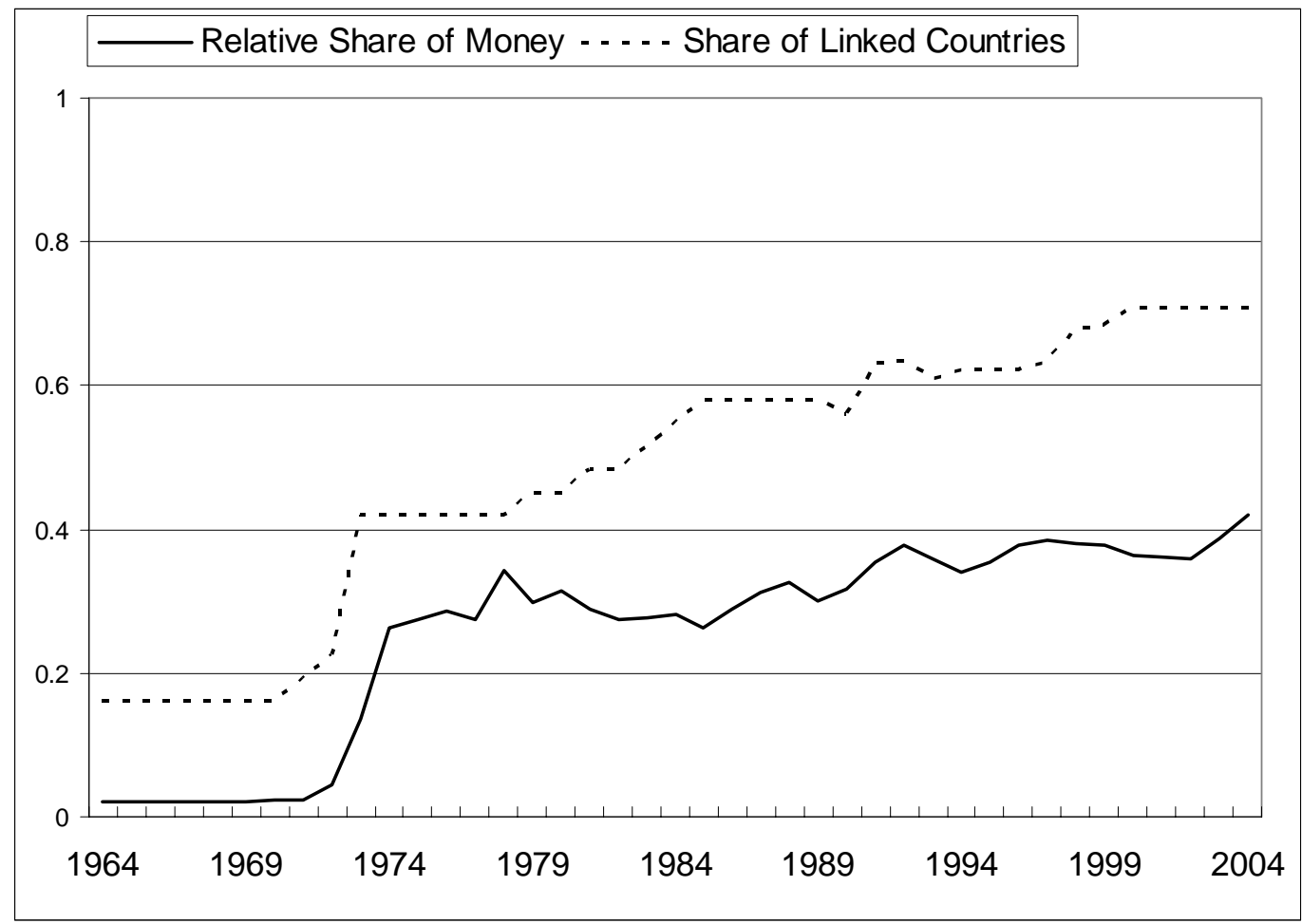

Figure 4. Inter-temporal Relative Share of Money and Countries Linked to the Japanese yen

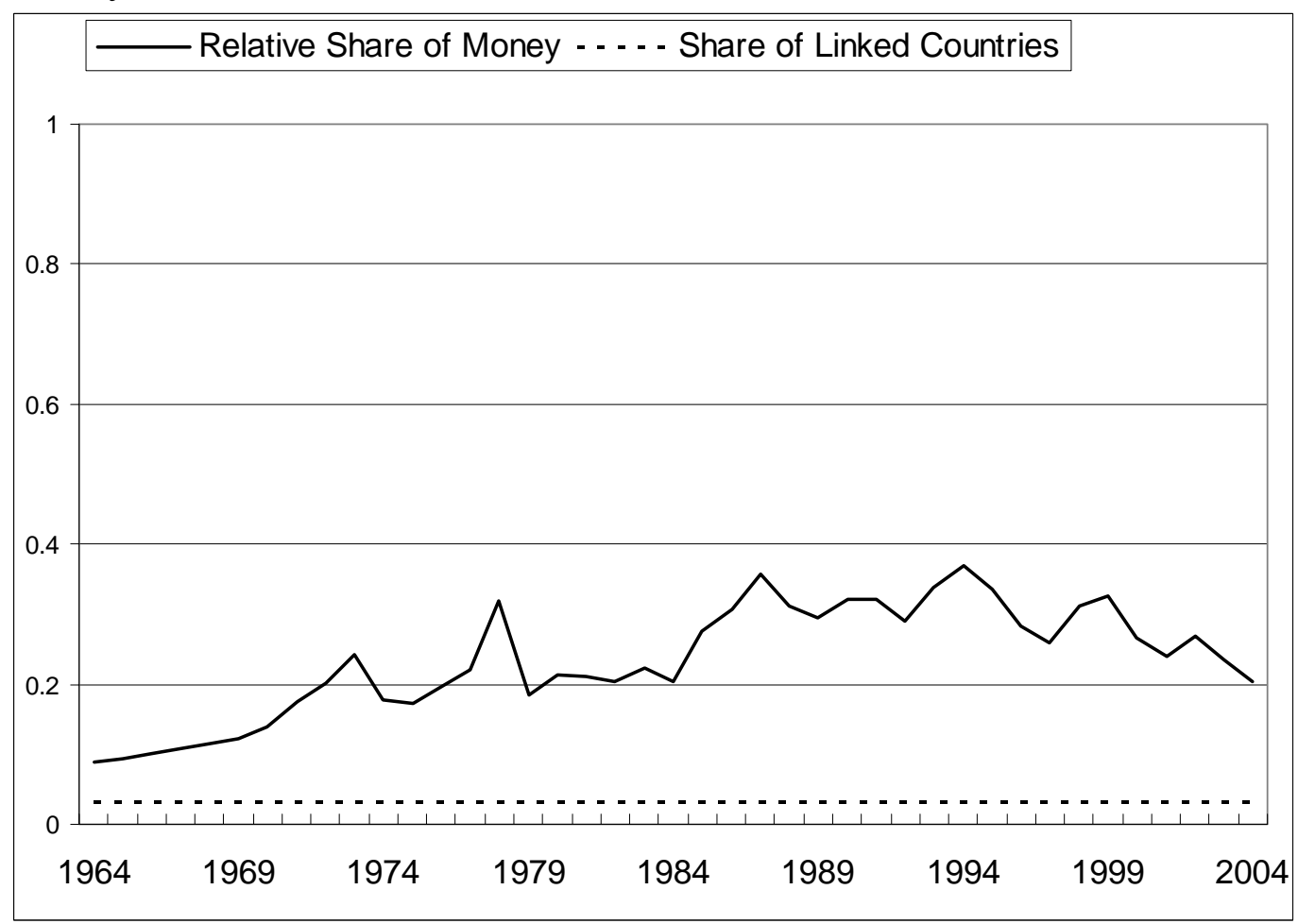


Figure 5. Inter-temporal Relative Share of Money and Countries Not-linked to any of the Anchor Currencies

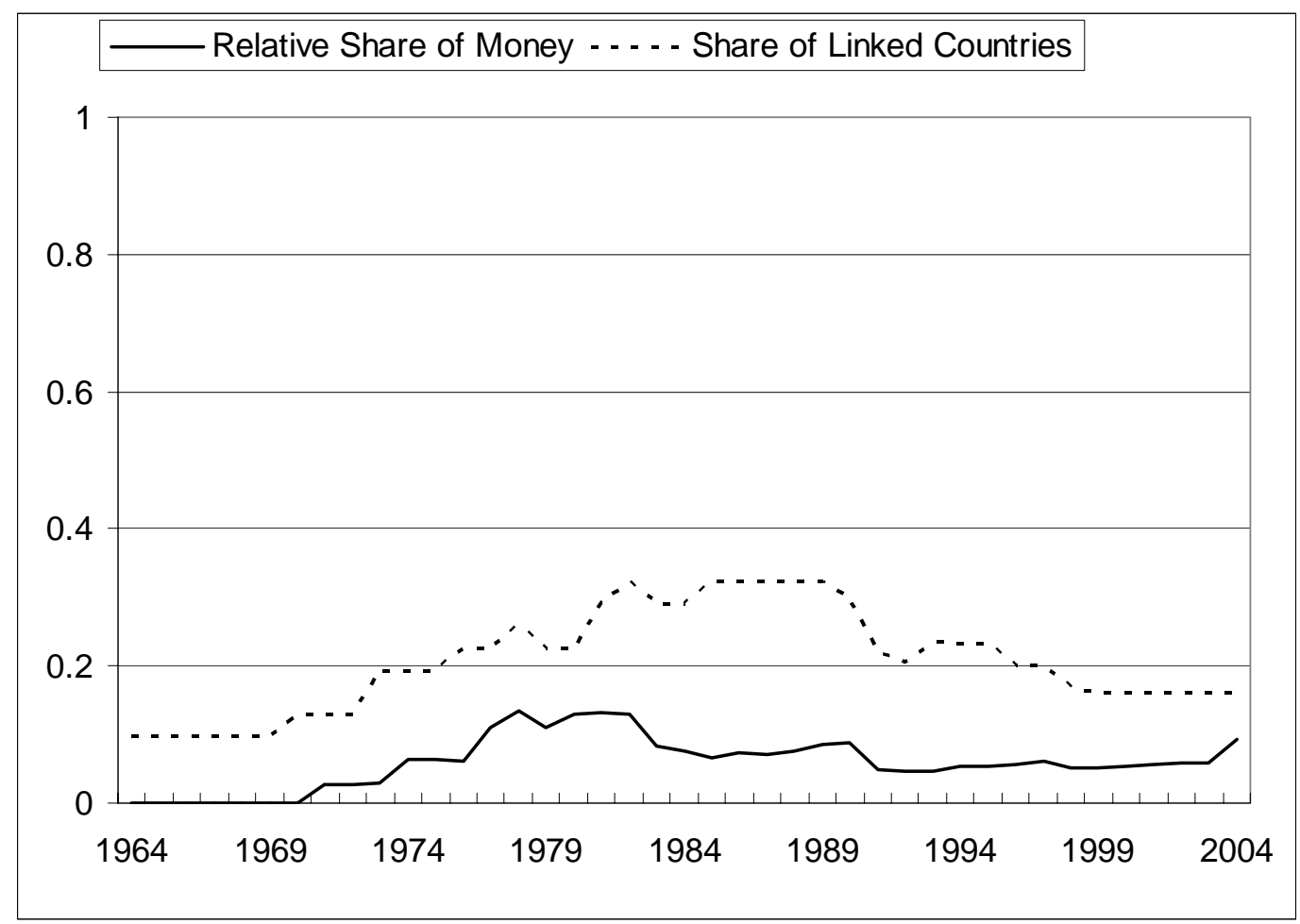

Figure 6. Relative Share of Money Linked to Anchor Currencies (1964-2004)

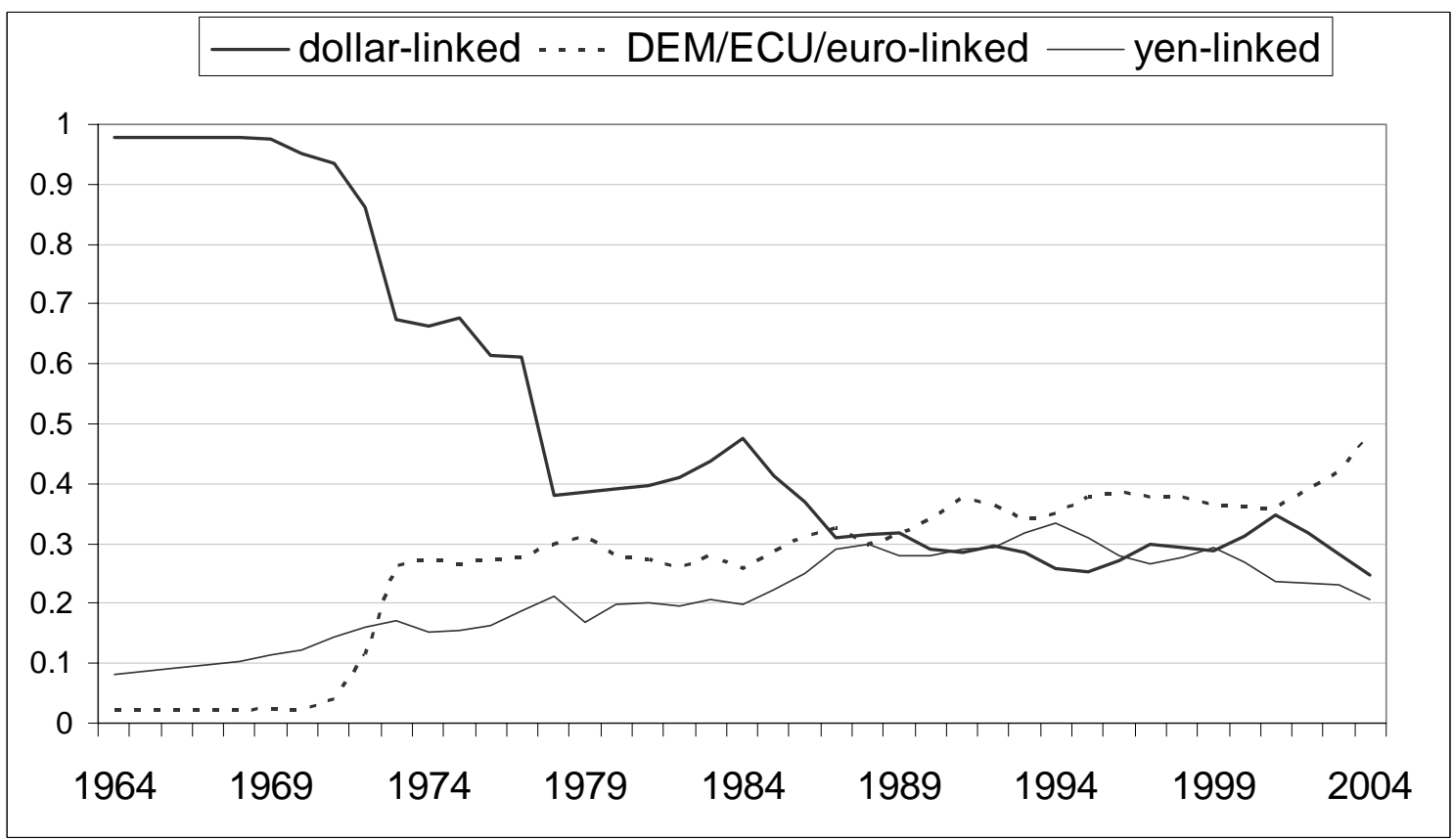


Figure 7. Short-term Interest Rates of the Anchor Currencies (1964-2004)

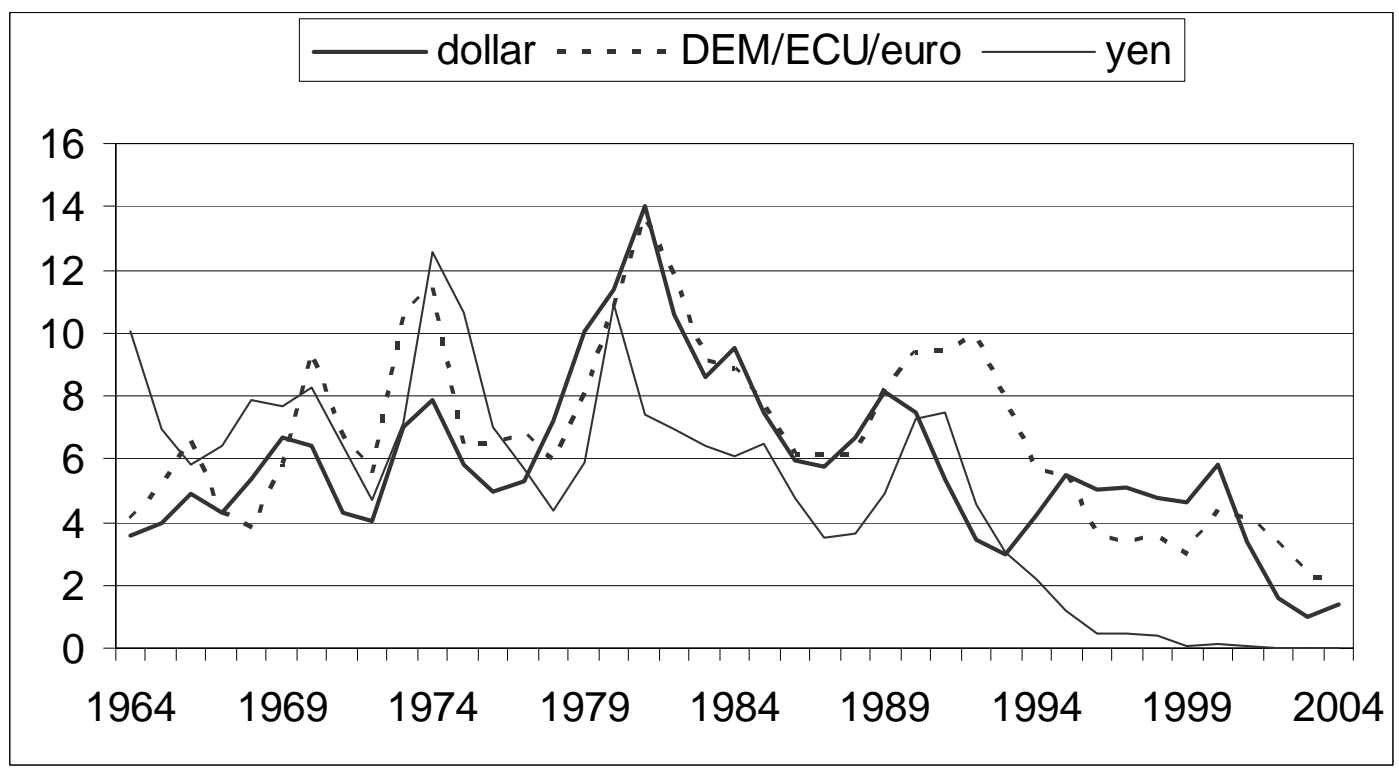

Figure 8. Time dynamics of goodness-of-fit $\left(\mathrm{R}^{2}\right)$ of the equation (2) computed on equidistant (15-years) time span from 1965 to 2004.

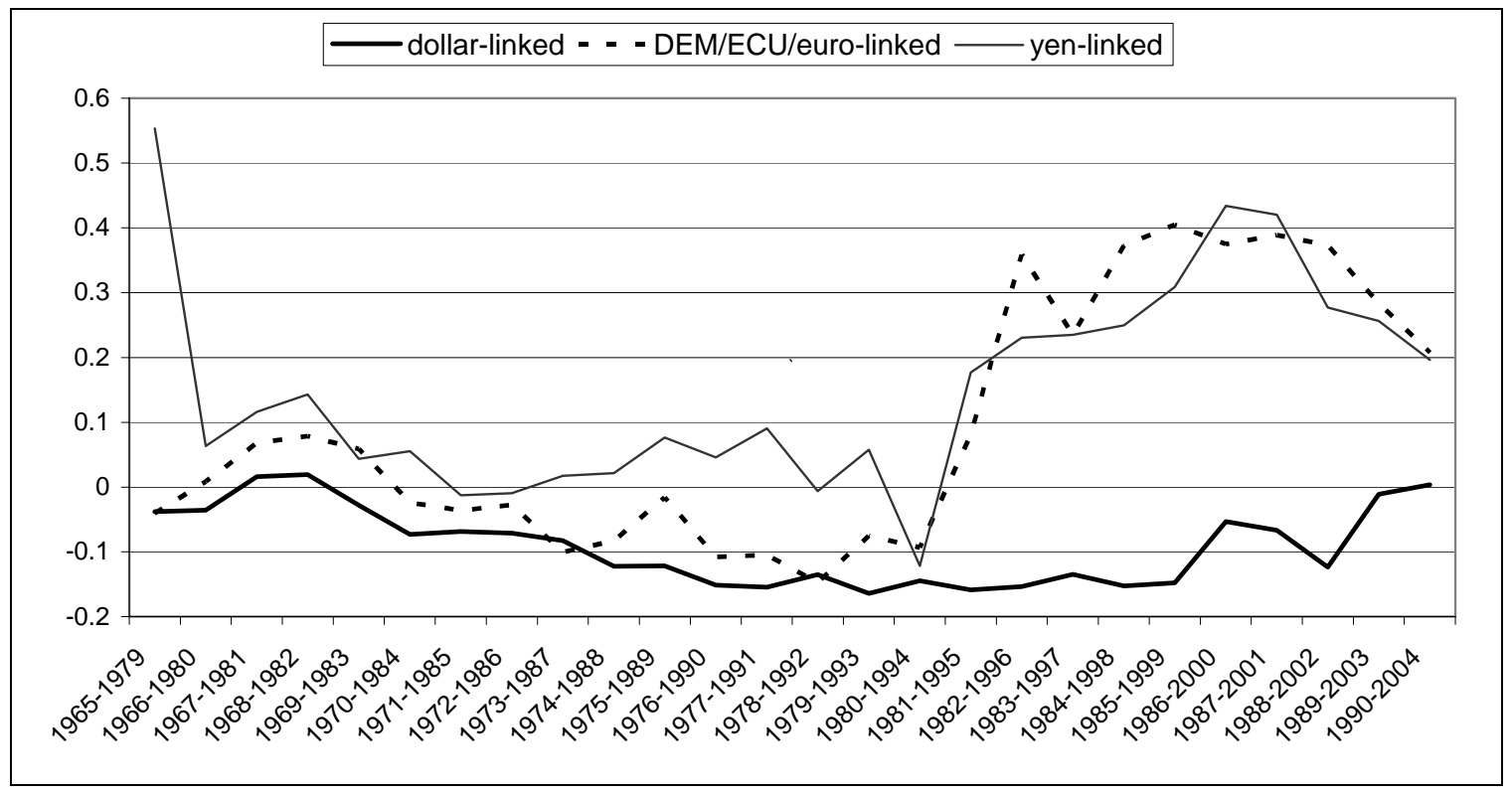


Table 1.

Rolling 15-year fixed windows IV estimates (monetary aggregate DM/ECU/euro-linked)

$$
\Delta M_{t}^{E U}=\alpha_{1} \Delta s r_{t-1}^{U S}+\alpha_{2} \Delta s r_{t-1}^{E U}+\alpha_{3} \Delta s r_{t-1}^{J P}
$$

$\begin{array}{lcccccc}\text { Period } & \text { sr(US) } & \text { p-Value } & \text { sr(EU) } & \text { p-Value } & \text { sr(JP) } & \text { p-Value } \\ 1965-1979 & -0.002 & 0.87 & -0.001 & 0.94 & -0.006 & 0.33 \\ 1966-1980 & -0.004 & 0.77 & -0.001 & 0.92 & -0.006 & 0.37 \\ 1967-1981 & -0.003 & 0.81 & 0.000 & 0.96 & -0.004 & 0.48 \\ 1968-1982 & -0.005 & 0.68 & -0.001 & 0.94 & -0.003 & 0.57 \\ 1969-1983 & -0.004 & 0.67 & -0.001 & 0.92 & -0.003 & 0.53 \\ 1970-1984 & -0.004 & 0.72 & 0.000 & 0.99 & -0.004 & 0.46 \\ 1971-1985 & -0.002 & 0.88 & -0.001 & 0.90 & -0.005 & 0.40 \\ 1972-1986 & -0.001 & 0.96 & -0.004 & 0.71 & -0.003 & 0.56 \\ 1973-1987 & -0.002 & 0.84 & 0.002 & 0.84 & -0.009 & 0.21 \\ 1974-1988 & -0.004 & 0.38 & 0.002 & 0.64 & -0.001 & 0.66 \\ 1975-1989 & -0.002 & 0.69 & -0.001 & 0.75 & -0.001 & 0.71 \\ 1976-1990 & -0.002 & 0.66 & 0.000 & 0.97 & -0.001 & 0.72 \\ 1977-1991 & -0.005 & 0.37 & 0.003 & 0.63 & 0.000 & 0.88 \\ 1978-1992 & -0.003 & 0.63 & 0.001 & 0.89 & -0.001 & 0.88 \\ 1979-1993 & -0.001 & 0.86 & -0.001 & 0.83 & 0.004 & 0.29 \\ 1980-1994 & -0.005 & 0.43 & 0.000 & 0.95 & 0.003 & 0.40 \\ 1981-1995 & 0.003 & 0.52 & -0.005 & 0.22 & 0.003 & 0.29 \\ 1982-1996 & 0.002 & 0.72 & -0.002 & 0.68 & 0.005 & 0.21 \\ 1983-1997 & 0.003 & 0.46 & -0.007 & 0.20 & 0.009 & 0.08 \\ 1984-1998 & 0.005 & 0.27 & -0.003 & 0.48 & 0.008 & 0.12 \\ 1985-1999 & 0.003 & 0.46 & -0.006 & 0.34 & 0.009 & 0.06 \\ 1986-2000 & 0.002 & 0.56 & -0.008 & 0.15 & 0.010 & 0.02 \\ 1987-2001 & 0.005 & 0.23 & -0.006 & 0.22 & 0.008 & 0.06 \\ 1988-2002 & 0.002 & 0.55 & -0.004 & 0.38 & 0.009 & 0.06 \\ 1989-2003 & 0.000 & 0.91 & -0.007 & 0.22 & 0.011 & 0.05 \\ 1990-2004 & -0.003 & 0.57 & -0.009 & 0.15 & 0.013 & 0.06\end{array}$

Note: $\operatorname{sr}(\mathrm{US}), \operatorname{sr}(\mathrm{EU})$ and $\operatorname{sr}(\mathrm{JP})$ stand for the US, European and Japanese short term interest rates, respectively. p-Value denotes statistical significance of the coefficients. 
Table 2.

Rolling 15-year fixed windows IV estimates (monetary aggregate dollar-linked)

$$
\Delta M_{t}^{U S}=\alpha_{1} \Delta s r_{t-1}^{U S}+\alpha_{2} \Delta s r_{t-1}^{E U}+\alpha_{3} \Delta s r_{t-1}^{J P}
$$

$\begin{array}{lcccccc}\text { Period } & \text { sr(US) } & \text { p-Value } & \text { sr(EU) } & \text { p-Value } & \text { sr(JP) } & \text { p-Value } \\ 1965-1979 & 0.008 & 0.75 & -0.002 & 0.86 & 0.013 & 0.23 \\ 1966-1980 & 0.001 & 0.95 & 0.001 & 0.92 & 0.011 & 0.32 \\ 1967-1981 & -0.003 & 0.90 & 0.002 & 0.91 & 0.010 & 0.39 \\ 1968-1982 & 0.003 & 0.90 & 0.001 & 0.92 & 0.005 & 0.58 \\ 1969-1983 & 0.000 & 0.99 & 0.003 & 0.83 & 0.004 & 0.73 \\ 1970-1984 & -0.003 & 0.88 & 0.002 & 0.90 & 0.009 & 0.39 \\ 1971-1985 & -0.006 & 0.73 & 0.004 & 0.78 & 0.010 & 0.33 \\ 1972-1986 & -0.008 & 0.69 & 0.008 & 0.65 & 0.009 & 0.41 \\ 1973-1987 & -0.006 & 0.78 & 0.003 & 0.86 & 0.012 & 0.34 \\ 1974-1988 & -0.001 & 0.95 & 0.001 & 0.97 & 0.004 & 0.65 \\ 1975-1989 & -0.003 & 0.84 & 0.005 & 0.77 & 0.006 & 0.48 \\ 1976-1990 & 0.003 & 0.86 & -0.001 & 0.96 & 0.010 & 0.34 \\ 1977-1991 & 0.003 & 0.86 & -0.007 & 0.73 & 0.004 & 0.66 \\ 1978-1992 & 0.003 & 0.85 & -0.008 & 0.67 & 0.007 & 0.54 \\ 1979-1993 & -0.001 & 0.89 & 0.000 & 0.97 & 0.000 & 0.91 \\ 1980-1994 & -0.001 & 0.91 & 0.003 & 0.75 & 0.002 & 0.68 \\ 1981-1995 & -0.001 & 0.91 & 0.003 & 0.68 & 0.002 & 0.72 \\ 1982-1996 & 0.001 & 0.84 & 0.001 & 0.93 & 0.001 & 0.81 \\ 1983-1997 & -0.001 & 0.84 & -0.001 & 0.91 & 0.003 & 0.73 \\ 1984-1998 & 0.002 & 0.74 & -0.006 & 0.46 & 0.005 & 0.55 \\ 1985-1999 & 0.005 & 0.47 & 0.000 & 0.99 & 0.002 & 0.85 \\ 1986-2000 & 0.008 & 0.17 & 0.000 & 0.97 & 0.000 & 0.97 \\ 1987-2001 & 0.005 & 0.45 & 0.000 & 0.96 & 0.001 & 0.85 \\ 1988-2002 & 0.003 & 0.58 & -0.003 & 0.61 & 0.001 & 0.89 \\ 1989-2003 & 0.005 & 0.25 & -0.001 & 0.87 & -0.001 & 0.92 \\ 1990-2004 & 0.007 & 0.14 & 0.001 & 0.92 & -0.002 & 0.79\end{array}$

Note: $\operatorname{sr}(\mathrm{US}), \operatorname{sr}(\mathrm{EU})$ and $\operatorname{sr}(\mathrm{JP})$ stand for the US, European and Japanese short term interest rates, respectively. p-Value denotes statistical significance of the coefficients. 
Table 3.

Rolling 15-year fixed windows IV estimates (monetary aggregate yen-linked)

$$
\Delta M_{t}^{J P}=\alpha_{1} \Delta s r_{t-1}^{U S}+\alpha_{2} \Delta s r_{t-1}^{E U}+\alpha_{3} \Delta s r_{t-1}^{J P}
$$

$\begin{array}{lcccccc}\text { Period } & \text { sr(US) } & \text { p-Value } & \text { sr(EU) } & \text { p-Value } & \text { sr(JP) } & \text { p-Value } \\ 1965-1979 & -0.012 & 0.00 & 0.005 & 0.05 & -0.001 & 0.76 \\ 1966-1980 & -0.005 & 0.36 & 0.002 & 0.41 & -0.001 & 0.63 \\ 1967-1981 & -0.005 & 0.31 & 0.003 & 0.39 & -0.001 & 0.82 \\ 1968-1982 & -0.006 & 0.22 & 0.003 & 0.40 & 0.000 & 1.00 \\ 1969-1983 & -0.006 & 0.14 & 0.003 & 0.34 & 0.001 & 0.80 \\ 1970-1984 & -0.007 & 0.08 & 0.004 & 0.18 & 0.000 & 0.86 \\ 1971-1985 & -0.005 & 0.24 & 0.003 & 0.36 & -0.001 & 0.62 \\ 1972-1986 & -0.005 & 0.34 & 0.002 & 0.66 & -0.001 & 0.79 \\ 1973-1987 & -0.006 & 0.28 & 0.003 & 0.56 & -0.002 & 0.60 \\ 1974-1988 & -0.007 & 0.19 & 0.004 & 0.39 & -0.001 & 0.79 \\ 1975-1989 & -0.007 & 0.17 & 0.005 & 0.30 & -0.001 & 0.70 \\ 1976-1990 & -0.009 & 0.09 & 0.007 & 0.18 & -0.003 & 0.34 \\ 1977-1991 & -0.010 & 0.05 & 0.010 & 0.09 & -0.002 & 0.48 \\ 1978-1992 & -0.008 & 0.12 & 0.008 & 0.20 & -0.001 & 0.79 \\ 1979-1993 & -0.008 & 0.07 & 0.007 & 0.17 & -0.001 & 0.77 \\ 1980-1994 & -0.004 & 0.46 & 0.002 & 0.74 & -0.002 & 0.54 \\ 1981-1995 & -0.008 & 0.01 & 0.004 & 0.25 & -0.002 & 0.38 \\ 1982-1996 & -0.009 & 0.01 & 0.004 & 0.28 & -0.003 & 0.28 \\ 1983-1997 & -0.008 & 0.01 & 0.004 & 0.33 & -0.003 & 0.50 \\ 1984-1998 & -0.010 & 0.01 & 0.007 & 0.12 & -0.004 & 0.34 \\ 1985-1999 & -0.011 & 0.00 & 0.004 & 0.45 & -0.003 & 0.53 \\ 1986-2000 & -0.014 & 0.00 & 0.006 & 0.26 & -0.002 & 0.66 \\ 1987-2001 & -0.014 & 0.00 & 0.002 & 0.68 & 0.000 & 0.92 \\ 1988-2002 & -0.009 & 0.03 & 0.003 & 0.50 & 0.000 & 0.97 \\ 1989-2003 & -0.007 & 0.05 & 0.004 & 0.38 & -0.001 & 0.86 \\ 1990-2004 & -0.007 & 0.09 & 0.006 & 0.27 & -0.002 & 0.74\end{array}$

Note: $\operatorname{sr}(\mathrm{US}), \operatorname{sr}(\mathrm{EU})$ and $\operatorname{sr}(\mathrm{JP})$ stand for the US, European and Japanese short term interest rates, respectively. p-Value denotes statistical significance of the coefficients. 


\section{Appendix}

\section{Proof of Proposition 1.}

(a) Assume $x_{1}=x_{2}$. In that case all satellite countries choose $c_{1}=c_{2}=\frac{1}{2}$. Hence $s_{1}=s_{2}=\frac{1}{2}$. By deviating to $x_{1}-\varepsilon$ or $x_{1}+\varepsilon$ with $\varepsilon>0$ very small, central bank 1 can capture $s_{1}=x_{1}-\varepsilon$ or $1-x_{1}-\varepsilon$ at a minimal increase in location costs. Hence unless $x_{1}=\frac{1}{2}$, central bank 1 has an incentive to deviate (as has central bank 2). Thus the only possible equilibrium with $x_{1}=x_{2}$ is $x_{1}=x_{2}=\frac{1}{2}$.

This is an equilibrium if the location costs are not too high for any of the banks. Consider first the case $p_{1}<\frac{1}{2}<p_{2}$. Observe that if $x_{1}<x_{2}$, $s_{1}=x_{1}+\int_{x_{1}}^{x_{2}} \frac{x_{2}-z}{x_{2}-x_{1}} d z=x_{1}+\frac{x_{2}-x_{1}}{2}=\frac{x_{1}+x_{2}}{2}$ and hence $\frac{\partial s_{1}}{\partial x_{1}}=\frac{1}{2}$. Thus also the derivative of $s_{i}$ from the left at $x_{1}=x_{2}=\frac{1}{2}$ equals $\frac{1}{2}$. Since $G_{i}^{\prime}\left(x_{i}\right)=s_{i}^{\prime}\left(x_{i}\right)-L^{\prime}\left(x_{i}-p_{i}\right)$, we get for the derivative from the left $G_{1}^{\prime}\left(\frac{1}{2}\right)>0$ if $L^{\prime}\left(\frac{1}{2}-p_{1}\right)=2 a\left(\frac{1}{2}-p_{1}\right) \leq \frac{1}{2}$ or $p_{1} \geq \frac{1}{2}-\frac{1}{4 a}$. In that case, 1 has no incentive to marginally deviate from $x_{1}=\frac{1}{2}$ to $x_{1}<\frac{1}{2}$ if $x_{2}=\frac{1}{2}$ since its loss in $s_{1}$ would not be compensated by a sufficient reduction of location costs. Since $L^{\prime \prime}>0$ a deviation to any $x_{1}<\frac{1}{2}$ would not pay. Clearly, a deviation to $x_{1}>\frac{1}{2}$ does not pay, because it would yield a smaller $s_{1}$ at higher location costs. Likewise, we derive for $p_{2}>\frac{1}{2}$ that the necessary and sufficient condition for 2 not to deviate to $x_{2}>\frac{1}{2}$ if $x_{1}=\frac{1}{2}$ is $L^{\prime}\left(\frac{1}{2}-p_{2}\right)=2 a\left(\frac{1}{2}-p_{2}\right) \geq-\frac{1}{2}$ or $p_{2} \leq \frac{1}{2}+\frac{1}{4 a}$ (since $\frac{\partial s_{2}}{\partial x_{2}}=-\frac{1}{2}$ for $x_{2}>x_{1}$ ).

Similarly, if $p_{2}>p_{1}>\frac{1}{2}$ then the condition for bank 1 changes to $L^{\prime}\left(\frac{1}{2}-p_{1}\right) \geq-\frac{1}{2}$ (which always holds if $L^{\prime}\left(\frac{1}{2}-p_{2}\right) \geq-\frac{1}{2}$ since $\left.L^{\prime \prime}>0\right)$ and for $\frac{1}{2}>p_{2}>p_{1}$ the condition for bank 2 changes to $L^{\prime}\left(\frac{1}{2}-p_{2}\right) \leq \frac{1}{2}$ (which always holds if $L^{\prime}\left(\frac{1}{2}-p_{1}\right) \leq \frac{1}{2}$ since $L^{\prime \prime}>0$ ).

(b) If $p_{1}<x_{1}<x_{2}<p_{2}$ and $L^{\prime}\left(x_{1}-p_{1}\right)=\frac{1}{2}\left(\Leftrightarrow 2 a\left(x_{1}-p_{1}\right)=\frac{1}{2} \Leftrightarrow x_{1}=p_{1}+\frac{1}{4 a}\right)$ and $L^{\prime}\left(x_{2}-p_{2}\right)=-\frac{1}{2} \quad\left(\Leftrightarrow 2 a\left(x_{2}-p_{2}\right)=-\frac{1}{2} \Leftrightarrow x_{2}=p_{2}-\frac{1}{4 a}\right)$ then since, as was shown above, $\frac{\partial s_{1}}{\partial x_{1}}=\frac{1}{2}$ and $\frac{\partial s_{2}}{\partial x_{2}}=-\frac{1}{2}, G_{1}^{\prime}\left(x_{1}\right)=G_{2}^{\prime}\left(x_{2}\right)=0$ and hence neither bank 1 nor bank 2 has an incentive to marginally deviate (note that $L^{\prime \prime}>0$ implies that if there is no incentive for a marginal deviation, there is also no incentive for a larger deviation that preserves $x_{1}<x_{2}$ ). In this case, $x_{1}<x_{2}$ is obviously equivalent to $p_{2}-p_{1}>\frac{1}{2 a}$.

Bank 1 would want to deviate from $x_{1}$ to $x_{2}+\varepsilon$ only if $\left(1-x_{2}\right)-\left(x_{1}+\frac{x_{2}-x_{1}}{2}\right)>L\left(x_{2}-p_{1}\right)-L\left(x_{1}-p_{1}\right)$, that is, the additional gain in currency holdings by switching to (a position slightly to the right of) $x_{2}$ will overcompensate the increase in location costs. ${ }^{35}$ Bank 1 would certainly not want to deviate to any larger $x$, because this would imply a smaller share at higher location costs. Note that there can only be an incentive to deviate to $x_{2}+\varepsilon$ if the preferred locations of the two anchor currency central banks are relatively close together but off the median of $f$. In other

\footnotetext{
${ }^{35}$ In the following, we will ignore $\varepsilon$ in the share and also in the costs because it can be arbitrarily small.
} 
words, such an equilibrium exists, if the preferred locations of both banks are located rather symmetrically around $\frac{1}{2}$, are relatively far apart, or location costs are high. Note that $L^{\prime}(0)=0$ implies $p_{1}<x_{1}<x_{2}<p_{2}$ since each bank would be willing to incur some location costs in order to increase its share $s_{i}$.

By somewhat tedious, but straightforward computation we can show that $\left(1-x_{2}\right)-\left(x_{1}+\frac{x_{2}-x_{1}}{2}\right) \leq L\left(x_{2}-p_{1}\right)-L\left(x_{1}-p_{1}\right) \Leftrightarrow 1-p_{2}-p_{1} \leq a\left(p_{2}-p_{1}\right)^{2}-\frac{1}{4 a}$ (note that the right-hand side is $>0$ since $\left.p_{2}-p_{1}>\frac{1}{2 a}\right)$.

Similarly, bank 2 has no incentive to deviate to $x_{1}-\varepsilon$ if $x_{1}-\left(1-x_{2}+\frac{x_{2}-x_{1}}{2}\right) \leq L\left(x_{1}-p_{2}\right)-L\left(x_{2}-p_{2}\right) \quad$ which is equivalent to $p_{2}+p_{1}-1 \leq a\left(p_{2}-p_{1}\right)^{2}-\frac{1}{4 a}$. Hence no bank has an incentive to deviate if $\left|1-p_{1}-p_{2}\right| \leq a\left(p_{2}-p_{1}\right)^{2}-\frac{1}{4 a}$.

(c) As was shown in (a) no equilibrium exists with $x_{1}=x_{2} \neq \frac{1}{2}$. Point (b) states necessary and sufficient conditions for an equilibrium with $p_{1}<x_{1}<x_{2}<p_{2}$. It is obvious that bank 1 would profit from deviating from an $x_{1}$ with $x_{1}<p_{1}<x_{2}$, $x_{1}<x_{2}<p_{1}, x_{2}<p_{1}<x_{1}$ or $p_{1}<x_{2}<x_{1}$ because 1 could simultaneously increase $s_{1}$ and lower location costs. Similarly, $x_{2}<p_{2}<x_{1}, \quad p_{2}<x_{1}<x_{2}, \quad x_{1}<p_{2}<x_{2}$ and $x_{2}<x_{1}<p_{2}$ are impossible. This covers all possible constellations of locations. If there is a "smallest policy unit $\varepsilon$ ", then there could in principle be constellations $x_{1}=x_{2}-\varepsilon<p_{1}$. Bank 1 would then not wish to deviate to $x_{2}$ (or anything larger) if $s_{1}>s_{2}$. In that case, however, bank 2 would want to deviate to $x_{1}$ (as long as $\varepsilon$ is small enough such that the increase in location costs is negligible). This situation leads to the requirement $\frac{1}{2}-\varepsilon \leq x_{1} \leq \frac{1}{2}$ and we are essentially back in case (a). The remaining cases with the smallest possible policy unit would be solved in a similar way. QED

\section{Proof of Proposition 2}

(a) Step 1: bank 2 does not want to deviate:

Note that for all $x_{2}$ with $x_{1}<x_{2}<x_{3}, s_{2}=\frac{1}{2}\left(x_{3}-x_{1}\right)$ and, hence, bank 2 has no incentive to deviate to any such $x_{2}$ since it will not affect $s_{2}$ but will cause positive location costs. If bank 2 deviates to $x_{2}=x_{1}-\varepsilon$, then its share is $x_{1}$ (we will again ignore $\varepsilon$ in the share and also in the costs because it can be arbitrarily small). Deviating does not pay, therefore, if $x_{1}-s_{2}{ }^{*} \leq L\left(x_{1}-p_{2}\right)$ which is (as again tedious but straightforward computation shows) equivalent to the first part of (3). If bank 2 deviates to $x_{1}$, then $s_{2}=\frac{s_{2}^{*}}{2}+\frac{x_{1}}{2}$, so if deviating to $x_{1}-\varepsilon$ does not pay, deviating to $x_{1}$ definitely does not pay. If bank 2 deviates to $x_{2}=x_{3}+\varepsilon$ then $s_{2}=1-x_{3}$; so deviating does not pay if $1-x_{3}-s_{2}{ }^{*} \leq L\left(x_{3}-p_{2}\right)$, which is equivalent to the first part of (4). If bank 2 deviates to $x_{3}$, then $s_{2}=\frac{s_{2}{ }^{*}}{2}+\frac{1-x_{3}}{2}$; so if deviating to $x_{3}+\varepsilon$ does not pay, then deviating to $x_{3}$ definitely does not pay.

Step 2: bank 1 does not want to deviate:

Since $L^{\prime}\left(x_{1}-p_{1}\right)=L^{\prime}\left(\frac{1}{4 a}\right)=\frac{1}{2}$ the marginal location costs of bank 1 at $x_{1}$ are equal to 
the marginal gain in $s_{1}$, hence bank 1 has no incentive to marginally deviate and condition (1) is equivalent to $x_{1} \leq p_{2}$. Since $L^{\prime \prime}>0$, bank 1 has no incentive to deviate to any $x<p_{2}$.

Bank 1 does not want to deviate to any $x$ with $p_{2}<x<x_{3}$ : Note that $s_{1}=\frac{x_{3}-p_{2}}{2}$ for all such $x$. Hence bank 1 would, if anything choose $p_{2}+\varepsilon$. Bank 1 will not deviate to $p_{2}+\varepsilon$ if $\frac{x_{3}-p_{2}}{2}-\frac{p_{2}+x_{1}}{2} \leq L\left(p_{2}-p_{1}\right)-L\left(x_{1}-p_{1}\right)$, which is equivalent to the second part of (3).

Bank 1 does not want to deviate to $x_{3}+\varepsilon$ because bank 2 does not want to deviate to $x_{3}+\varepsilon$, as can be seen by the following argument. For ease of notation let $A=x_{1}$, $B=p_{2}-x_{1}, C=x_{3}-p_{2}$ and $D=1-x_{3}$. Assume that bank 1 wants to deviate to $x_{3}+\varepsilon$, i.e. $D-A-\frac{B}{2}>a\left(x_{3}-p_{1}\right)^{2}-a\left(x_{1}-p_{1}\right)^{2}$, but bank 2 does not, i.e. $D-\frac{C+B}{2} \leq a\left(x_{3}-p_{2}\right)^{2}$. Observe that

$$
\begin{aligned}
& a\left(x_{3}-p_{1}\right)^{2}-a\left(x_{1}-p_{1}\right)^{2}=a\left(x_{3}-p_{2}+p_{2}-p_{1}\right)^{2}-a\left(x_{1}-p_{1}\right)^{2}= \\
& =a\left(x_{3}-p_{2}\right)^{2}+a\left(p_{2}-p_{1}\right)^{2}-a\left(x_{1}-p_{1}\right)^{2}+2 a\left(x_{3}-p_{2}\right)\left(p_{2}-p_{1}\right) \geq a\left(x_{3}-p_{2}\right)^{2}+\frac{C}{2}
\end{aligned}
$$

Hence, the above assumptions imply that $D-A-\frac{B}{2}>a\left(x_{3}-p_{2}\right)^{2}+\frac{C}{2} \geq D-\frac{B}{2}$, which can obviously not be true.

By deviating to $p_{2}$, bank 1 would obtain the average of the shares that it obtains at $p_{2}-\varepsilon$ and $p_{2}+\varepsilon$, so if it does not want to deviate to either of these, it does not want to deviate to $p_{2}$ either, and by a parallel argument it does not want to deviate to $x_{3}$.

Deviating to any other location is dominated because it yields the same or a lower $s_{1}$ at a higher location cost than one of the options discussed above.

Step 3: bank 3 does not want to deviate:

The situation of bank 3 is symmetric to that of bank 1 and hence the conditions are derived in a completely parallel way.

The above analysis shows that conditions (1) to (4) are sufficient for $\left(x_{1}, p_{2}, x_{3}\right)$ being an equilibrium, but also necessary for an equilibrium with $x_{1}<p_{2}<x_{3}$ and $x_{1}<x_{2}<x_{3}$.

(b) Step 1: banks 1 and 2 do not want to deviate: Note that since $3 x_{1}=x_{3}$ we have $x_{1}=\frac{x_{3}-x_{1}}{2}$, so deviations to $x$ with $x_{1}<x<x_{3}$ also yield $s=\frac{x_{3}-x_{1}}{2}=x_{1}$ but since $p_{1}<p_{2} \leq x_{1}$ the location costs are higher. A deviation to $x<x_{1}$ implies a reduction of $s$ by $\frac{x_{1}-x}{2}$. Since $x_{1}-p_{2}<x_{1}-p_{1} \leq \frac{1}{4 a}$, we have $L^{\prime}\left(x_{1}-p_{2}\right)<L^{\prime}\left(x_{1}-p_{1}\right) \leq \frac{1}{2}$. Thus the decrease in location costs is smaller than the loss in $\mathrm{s}$ and a deviation to $x<x_{1}$ does not pay. Finally, a deviation to $x_{3}+\varepsilon$ does not pay for bank 2 if $1-x_{3}-x_{1} \leq L\left(x_{3}-p_{2}\right)-L\left(x_{1}-p_{2}\right)$, which is equivalent to (5). Since $L^{\prime \prime}>0$ and $p_{1}<p_{2}$, deviating to $x_{3}+\varepsilon$ does not pay for bank 1 if it does not pay for bank 2 .

Step 2: bank 3 does not want to deviate: since $x_{3}=p_{3}-\frac{1}{4 a}, L^{\prime}\left(x_{3}-p_{3}\right)=-\frac{1}{2}$ and hence bank 3 does not want to deviate to any $x>x_{1}$. Since $s_{3}{ }^{*}>\frac{1}{3}>x_{1}$, a deviation to $x_{1}-\varepsilon$ or 
$x_{1}$ implies a lower share at a higher location cost and hence bank 3 has no incentive to deviate.

(c) This is just the symmetric situation to (b). The proof is essentially identical.

(d) There are no further equilibria.

Step 1: as established above, the equilibrium in (a) is the only equilibrium with $x_{1}<p_{2}<x_{3}$ and $x_{1}<x_{2}<x_{3}$. There can be no equilibrium with $x_{1}<x_{2}<x_{3}$ but $p_{2} \leq x_{1}$, because in that case bank 2 could, by deviating to $x$ with $x_{1}<x<x_{2}$, obtain the same $s_{2}$ at lower location costs. ${ }^{36}$ By a parallel argument, there is also no equilibrium with $x_{1}<x_{2}<x_{3}$ but $x_{3} \leq p_{2}$. Hence the equilibrium in (a) is the only equilibrium with $x_{1}<x_{2}<x_{3}$.

Step 2: $x_{1}=x_{2}<x_{3}$ implies $x_{1}=\frac{x_{3}-x_{1}}{2}$ otherwise bank 1 or 2 could, by a marginal deviation, increase its share at essentially 0 increase in location costs. This then implies $p_{1}<p_{2} \leq x_{1}$ because any $x$ with $x_{1}<x<x_{3}$ yields the same share, so if $p_{2}>x_{1}$, bank 2 could obtain the same share at lower location costs. Hence the equilibrium in (b) is the only equilibrium with $x_{1}=x_{2}<x_{3}$.

Step 3: by the same argument as in step 2, the only equilibrium with $x_{1}<x_{2}=x_{3}$ is the equilibrium in (c).

Step 4: $x_{1}=x_{2}=x_{3}$ cannot be an equilibrium: in this case $s_{i}=\frac{1}{3}$ and by a marginal deviation bank $i$ could obtain $\max \left(x_{1}, 1-x_{1}\right) \geq \frac{1}{2}$.

Step 5: in equilibrium $x_{2}<x_{1} \leq x_{3}$ is impossible, because in that case $p_{1}<x_{1}$ or $x_{2}<p_{2}$ and, hence, one bank could lower its location costs while increasing or retaining its share (note that as was argued in the proof of part (b), if in equilibrium $x_{1}=x_{3}$ then $\frac{x_{3}-x_{2}}{2}=1-x_{3}$, so by deviating to $x$ with $x_{2}<x<x_{3}$, bank 1 would obtain the same $s_{1}$, as it is also the case for $x_{1}<x_{3}$ ). On the other hand, $x_{2}=x_{1}<x_{3}$ corresponds to the equilibrium in (b), so all cases $x_{2} \leq x_{1} \leq x_{3}$ are covered (in case of equality of all $x$, step 4 applies).

Step 6: the argument why any constellation, $x_{1} \leq x_{3}<x_{2}, x_{2} \leq x_{3} \leq x_{1}, x_{3} \leq x_{2} \leq x_{1}$, $x_{3} \leq x_{1} \leq x_{2}$ cannot occur in equilibrium is the same as in step 5: at least one bank can reduce its location costs without reducing its share if at least one inequality is strict; otherwise the argument of step 4 applies.

This covers all possible constellations of $x_{1}, x_{2}$, and $x_{3}$ and shows that no equilibrium except for those in (a), (b), and (c) exist. QED

\footnotetext{
${ }^{36}$ If there is a "smallest policy unit $\varepsilon$ " then there could be an equilibrium where $x_{1}<x_{2}<x_{3}$ but $p_{2} \leq x_{1}$, namely if $x_{2}=x_{1}+\varepsilon$ and $s_{2}$ is larger than $s_{1}$, but in that case bank 1 would have an incentive to deviate to $x_{2}$, unless the difference in shares is very small, so this essentially corresponds to the equilibrium in (b).
} 